\title{
Assessing the Coupled Influences of Clouds on the Atmospheric Energy and Water Cycles in Reanalyses with A-Train Observations
}

\author{
A. S. DALOZ \\ Space and Science Engineering Center, and Center for Climatic Research, University of \\ Wisconsin-Madison, Madison, Wisconsin \\ E. NELSON \\ Atmospheric and Oceanic Sciences Department, University of Wisconsin-Madison, Madison, Wisconsin \\ T. L'ECUYER \\ Center for Climatic Research, and Atmospheric and Oceanic Sciences Department, University of \\ Wisconsin-Madison, Madison, Wisconsin \\ A. D. RAPP AND L. SUN \\ Department of Atmospheric Sciences, Texas A\&M University, College Station, Texas
}

(Manuscript received 2 January 2018, in final form 29 June 2018)

\begin{abstract}
The lack of complete knowledge concerning the complex interactions among clouds, circulation, and climate hinders our ability to simulate the Earth's climate correctly. This study contributes to a broader understanding of the implications of cloud and precipitation biases on the representation of coupled energy and water exchanges by bringing together a suite of cloud impact parameters (CIPs). These parameters measure the coupled impact of cloud systems on regional energy balance and hydrology by simultaneously capturing the absolute strength of the cloud albedo and greenhouse effects, the relative importance of these two radiative effects, and the efficiency of precipitating clouds to radiatively heat the atmosphere and cool the surface per unit of heating through rain production. Global distribution of these CIPs is derived using satellite observations from CloudSat and used to evaluate energy and water cycle coupling in four reanalysis datasets [both versions of the Modern-Era Retrospective Analysis for Research and Applications (MERRA and MERRA-2); the European Centre for Medium-Range Weather Forecasts (ECMWF) interim reanalysis (ERA-Interim); and the Japanese 55-year Reanalysis (JRA-55)]. The results show that the reanalyses provide a more accurate representation of the three radiation-centric parameters than the radiative efficiencies. Of the four reanalyses, MERRA and ERA-Interim provide the best overall representation of the different cloud processes but can still show significant biases. JRA-55 exhibits some clear deficiencies in many parameters, while MERRA-2 seems to introduce biases that were not evident in MERRA.
\end{abstract}

\section{Introduction}

Clouds influence our climate by modulating fluxes of energy between the surface (SFC) and the atmosphere and by transporting energy throughout the atmosphere through diabatic heating. Their impact is apparent at many spatial and temporal scales: from the organization of mesoscale convective systems (Houze 1982, 1989; Mapes and Houze 1995) and the evolution of extratropical

Corresponding author: Anne Sophie Daloz, adaloz@wisc.edu cyclones (Weaver 1999) to the propagation speed of tropical intraseasonal oscillations (Lau and Peng 1987; Lee et al. 2001) and the strength of the Hadley and Walker circulations (Slingo and Slingo 1988, 1991; Hartmann et al. 1984; Schumacher et al. 2004). In addition, cloud feedbacks are intimately connected to associated changes in precipitation efficiency, or the effectiveness of different processes in converting cloud condensate to surface precipitation (e.g., Stevens and Bony 2013; Bony et al. 2015).

However, metrics for examining cloud processes and their relationship with precipitation are currently 
limited. Mean values of cloud cover or cloud fraction are often employed to evaluate observations or models (e.g., Walsh et al. 2009; Clark and Walsh 2010; Dolinar et al. 2016), providing interesting information on the representation of the proportion of clouds, but their use alone provides limited insights into the underlying cloud processes. Cloud cover or fraction is also difficult to compare between models and observations, as the classification technique differs within each dataset (Kay et al. 2012). Compounding the difficulty in assessing cloud impacts is their dependence on several other factors, including the location, height, and optical depth, which in turn depend on the hydrometeor size, phase, and water content-factors not accounted for in measurements of cloud fraction. These cloud morphology characteristics of clouds are especially important in cases of cloud overlap. As Jakob and Klein (1999, 2000) showed, providing information about the vertical variation in cloud fraction has a great impact not only on radiation processes, but also on precipitation processes such as the efficiency of precipitation or evaporation. Alternatively, when examined in isolation, accumulated precipitation provides a metric for assessing regional hydrology but lacks information linking water cycle biases to cloud feedbacks or the underlying physical processes that governed the transition from cloud to precipitation. Therefore, recent studies (e.g., Soden 2000; Pincus et al. 2008; Nam and Quaas 2012) began connecting cloud and precipitation in their evaluation of reanalyses and climate models. Recognizing the connection between precipitation and cloud radiative effects (CREs) and the need for a better representation of cloud processes in models, this investigation builds on these studies by bringing together five cloud impact parameters (CIPs) that collectively capture the energetic signatures associated with high cloud, low cloud, and hydrologic cycle feedbacks and quantifying their global distribution.

The CIPs measure the strength of the cloud albedo $\left(A_{\text {cld }}\right)$ and greenhouse $\left(G_{\text {cld }}\right)$ effects, their ratio $(N)$, and the efficiency of precipitating clouds to radiatively heat the atmosphere $\left(R_{h}\right)$ and cool the surface $\left(R_{c}\right)$ per unit rain rate. These last two parameters are particularly interesting because they provide a direct link between radiative fluxes and the environment via precipitation. These parameters have been introduced in various forms in the literature, but to date, there has been no comprehensive survey of the links between them. The cloud albedo $\left(A_{\text {cld }}\right)$ and greenhouse $\left(G_{\text {cld }}\right)$ effects have been previously examined globally using observations (e.g., Stephens and Greenwald 1991). Quantitative analysis of the ratio of top-of-atmosphere (TOA) shortwave (SW) and longwave (LW) CRE has generally been restricted to tropical regions, where they often cancel (Kiehl 1994). The efficiency of precipitating clouds to radiatively heat the atmosphere $\left(R_{h}\right)$ and cool the surface $\left(R_{c}\right)$ relative to their heating by precipitation yield is rooted in parameterizing cloud effects in simple models (Sobel and Bretherton 2000). Yet, these last two parameters are particularly relevant for constraining the strength of global feedbacks owing to the direct link between atmospheric radiative cooling and latent heating in Earth's radiation budget (Soden and Held 2006; Stephens and Ellis 2008). Observational estimates of $R_{c}$ and $R_{h}$ in the tropical Pacific were presented in L'Ecuyer et al. (2006) in the context of illustrating the coupled energy and water cycle influence on El Niño-Southern Oscillation (ENSO), but few studies, if any, have quantified these parameters on global scales, and none have examined them in the context of the other radiation-centric impact parameters. Here, $R_{c}$ and $R_{h}$ are quantified on global scales and in the context of the other radiation-centric CIPs for the first time. By explicitly representing coupling among LW, SW, and latent heat fluxes, the ensemble of CIPs examined here provides considerably tighter constraints on physical processes than any single parameter in isolation. Another advantage of these parameters is that they are based on variables that are provided consistently among the satellite observations, reanalyses, and climate models, so they allow a direct evaluation of the latter while avoiding the ambiguities inherent in defining cloud and precipitation occurrence.

This study initially documents the global distributions of the CIPs using satellite observations. From an observational perspective, recently launched active satellite instruments allow explicit vertical interrogation of the atmosphere remotely. The synergistic instruments flying in a formation called the Afternoon Constellation (or A-Train) provide the diverse observations required to generate vertically resolved profiles of broadband radiative fluxes throughout the atmosphere and associated surface precipitation (e.g., L'Ecuyer et al. 2008; Haynes et al. 2009; Kummerow et al. 2011). While the time period of data available from active sensors is more limited, compared to legacy passive radiative measurements, active sensors provide explicit vertical structure information, allowing tighter constraints on surface fluxes and improving the sensitivity to light precipitation. Top-of-the-atmosphere fluxes from these new observations compare well against conventional broadband flux observations in clear-sky cases with some expected differences in the case of all-sky conditions due to improved sensitivity by the active instruments (Henderson et al. 2013; Matus and L'Ecuyer 2017). These derived radiative fluxes and associated 
precipitation observations provide a direct comparison to three-dimensional fluxes that are available from the reanalyses for the evaluation of radiative constraints.

The CIPs are then used to evaluate four modern reanalyses: the Modern-Era Retrospective Analysis for Research and Applications (MERRA), MERRA-2, the European Centre for Medium-Range Weather Forecasts (ECMWF) interim reanalysis (ERA-Interim), and the Japanese 55-year Reanalysis (JRA-55). Reanalyses combine the outputs from numerical weather prediction models and assimilated data from several observational platforms to address a variety of applications. In climate studies, they are often used as a reference for calibrating models and are often considered analogous observations (e.g., Daloz et al. 2012; Dixon et al. 2017). A core strength is their continuous coverage, both spatially and temporally, using a combination of satellite and in situ observations assimilated into the dynamical core of their model. Reanalysis datasets can reproduce state variables, such as wind or temperature, with some systematic errors that can differ depending on the dataset examined (e.g., Reichler and Kim 2008). However, because reanalyses are based on both models and observations, they often exhibit systematic and varied biases, especially in stochastic variables like cloud and precipitation. Furthermore, each reanalysis dataset is based on a different dynamical core that may parameterize or resolve physical processes differently. Each reanalysis may also assimilate different observation datasets. Both of these structural differences may impact their representation of the coupled energy and water cycle influences of precipitating cloud systems. Providing an estimate of the ability of reanalyses to accurately represent cloud and precipitation processes is essential to determine areas where the climate energetics are appropriately represented to support their use in climate studies and as references for the evaluation of unconstrained models. In addition, examining the ability of reanalyses to represent cloud processes is an intermediary step toward ultimately analyzing climate models to hopefully narrow the spread in future projections.

The evaluation of reanalyses on these features is not a new concept and has been the subject of a number of recent studies. Heng et al. (2014), for example, showed a good agreement in the representation of the global distribution of cloud water in two reanalyses versus satellite observations. Dolinar et al. (2016) evaluated five reanalysis datasets versus satellite observations. They showed that clouds are overpredicted (underpredicted) in the ascent (descent) regime and that biases are often larger in the ascent regime. In parallel, precipitation is overpredicted in both regimes. Over the poles, Walsh et al. (2009) found that reanalyses simulate radiative fluxes correctly when the cloud fraction is simulated correctly. Unfortunately, they also showed that the errors in cloud fraction are important. Over the Arctic, Liu and Key (2016) showed that reanalyses are able to represent monthly mean cloud anomalies, but they show significant differences in terms of cloud amount. In addition, Lenaerts et al. (2017) showed that reanalyses have important biases in liquid and/or ice water. Over the Asian monsoon region, Li et al. (2017) also identified strong biases in several reanalysis datasets in cloud fraction and LW and SW radiation. This investigation seeks to expand these comparisons by measuring the link between the processes of the energy and water cycles that ultimately result in biases of cloud fraction globally.

The next section presents the details of datasets employed in this study, of both observational and reanalysis nature, and defines the CIPs. Section 3 presents and documents the climatology of the CIPs in the CloudSat satellite observations, while section 4 evaluates the CIP representation in four modern reanalyses (MERRA, MERRA-2, ERA-Interim, and JRA-55). Section 5 presents two concrete examples of what we can learn with the CIPs via the representation of the seasonal cycle over the Indo-Pacific warm pool and the stratocumulus region off the California coast. Finally, section 6 summarizes and discusses the results.

\section{Data and methodology}

\section{a. Observations}

Radiative flux observations are drawn from operational CloudSat products. CloudSat is a polar-orbiting satellite with a $98^{\circ}$ orbital inclination equipped with the $94-\mathrm{GHz}$ (W band) Cloud Profiling Radar (CPR; Stephens et al. 2008, 2017; L'Ecuyer and Jiang 2010). The CPR has a minimum detectible reflectivity near $-30 \mathrm{~dB} Z$, which provides a high sensitivity to clouds and precipitation (Tanelli et al. 2008). Radiative fluxes derive from the CloudSat algorithm 2B-FLXHR-lidar (2BFLX). 2BFLX blends information from the A-Train including CloudSat's CPR, the CALIPSO satellite's lidar instrument CALIOP, and the Moderate Resolution Imaging Spectroradiometer and Advanced Microwave Scanning Radiometer for Earth Observing System instruments on the Aqua satellite to generate vertically resolved profiles of broadband radiation using a radiative transfer model (L'Ecuyer et al. 2008; Henderson et al. 2013). The R05 version of this product adopted here includes improved surface albedo estimates and explicit treatment of mixed-phase clouds (Matus and L'Ecuyer 2017). 
Observations cover the period from January 2007 to December 2010, as this was the time period when CloudSat operated at all orbit times (before later switching to daytime observations only). Since the A-Train is in low Earth orbit with a high inclination, the observations do not adequately capture the global variation of solar insolation across the complete diurnal cycle. To account for this limitation in this study, a special version of 2BFLX is adopted that is designed to provide shortwave fluxes more representative of diurnally averaged values. This is accomplished by varying the solar zenith angle in 2-h increments to simulate conditions at all times of day. The resulting fluxes are then averaged to monthly, $2.5^{\circ}$ resolution and rescaled to the monthly mean solar insolation to correct for any additional sampling biases. This does not capture complete diurnal variations that are not sampled by the A-Train, but it provides a robust means for accounting for the diurnal cycle of solar insolation when observations are taken.

Precipitation estimates are principally obtained from GPCP version 2.2, a merged rainfall product that uses observations from polar orbiting microwave sensors to train geosynchronous and polar orbiting infrared sensors of greater coverage with additional calibration over land using ground gauges (Adler et al. 2003; Huffman et al. 2009). Since passive sensors have some difficulty in sensing shallow, isolated warm rain due to its proximity to the surface and small spatial scale (Haynes et al. 2009), GPCP is augmented with CloudSat rainfall estimates in regions dominated by warm rain. The Wisconsin Algorithm for Latent Heating and Rainfall Using Satellites (WALRUS), an algorithm applied to CloudSat focused on retrieving warm rain (Nelson et al. 2016), is adopted for this purpose, but only the surface rainfall product is used. For each month of observation, the maximum rainfall rate between the two products is chosen as the rainfall amount for a given grid box. The number of months CloudSat rainfall estimates are selected instead of GPCP for each grid box is shown in Fig. 1. We argue that this merged rainfall product better accounts for the rainfall contribution from all precipitation regimes, particularly in subsidence regions dominated by marine stratocumulus and warm rain.

While the analysis has corrected for some issues related to the time of day and corresponding solar insolation, it cannot change the sampling frequency of the satellite. The predetermined equatorial crossings at 0130 and 1330 local time may not allow for a full sampling of the diurnal cycle of convection that exists, especially in tropical regions (Nesbitt and Zipser 2003). In spite of this sampling limitation, radiative fluxes from CloudSat are mostly in agreement with another

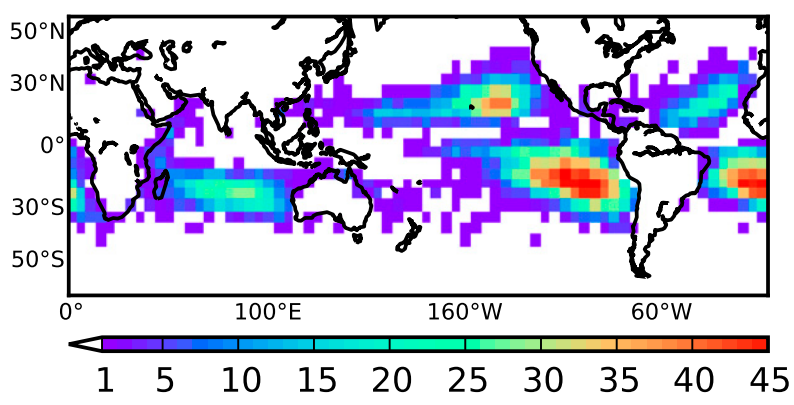

FIG. 1. Map of the frequency CloudSat is adopted in each grid box (i.e., fraction of all months for which CloudSat replaced GPCP).

observation radiative product, namely, the Clouds and the Earth's Radiant Energy System (CERES; Matus and L'Ecuyer 2017). In their comparison of global estimates from CloudSat and CERES, Matus and L'Ecuyer (2017) found differences of $-2.0 \mathrm{~W} \mathrm{~m}^{-2}$ in shortwave radiation and $-3.7 \mathrm{Wm}^{-2}$ in longwave radiation. Recent estimates of GPCP biases are less than $10 \%$, with ocean biases generally higher than land, given the lack of gauge data (Adler et al. 2012), while WALRUS rainfall estimates are globally biased around $-12 \%$, compared to other CloudSat rainfall products, though these datasets are, themselves, inherently uncertain (Nelson and L'Ecuyer 2018).

\section{b. Reanalyses}

This study compares four modern reanalyses: MERRA, MERRA-2, ERA-Interim, and JRA-55. Their characteristics and some of their differences are listed in this section.

\section{1) MERRA}

MERRA (Rienecker et al. 2011; $0.67^{\circ} \times 0.5^{\circ} \times 42$ levels) uses the Goddard Earth Observing System version 5 (GEOS-5) and the data assimilation system (DAS). This atmospheric general circulation model uses a prognostic cloud parameterization scheme (Bacmeister et al. 2006). This scheme assumes a maximum-random overlap and uses the SW radiation scheme from Chou and Suarez (1999) and the LW radiation scheme from Chou et al. (2001). To constrain the atmospheric model with observations, MERRA uses an assimilation process called incremental analysis update (IAU; Bloom et al. 1996). IAU slowly adjusts the model states toward the observed state. To resolve boundary layer clouds, two turbulent mixing schemes are incorporated. When there are no boundary layer clouds in stable conditions, they use Louis et al. (1982), but when the conditions are unstable or for cloud-topped boundary layers, Lock et al. (2000) is employed. 


\section{2) MERRA-2}

MERRA-2 (Gelaro et al. 2017; Bosilovich et al. 2015; $0.635^{\circ} \times 0.5^{\circ} \times 42$ levels) was recently introduced to replace MERRA. In the new version, improvements are made in the GEOS-5 model and the assimilation system. MERRA-2 is the first long-term reanalysis that assimilates space-based observations of aerosol. After 2005, ozone observations are included. The new system enables assimilation of modern hyperspectral radiance and microwave observations as well as GPS radio occultation datasets. Spatial resolution remains about the same between the two MERRA reanalysis datasets. Several upgrades have been made to the physical parameterization schemes, including an increase in reevaporation of frozen precipitation and cloud condensate (Molod et al. 2015). The new reanalysis dataset now contains a Tokioka-type trigger on deep convection as part of the relaxed Arakawa-Schubert convective parameterization scheme (Moorthi and Suarez 1992). A new glaciated land representation and seasonally varying sea ice albedo have also been incorporated in the reanalysis, which leads to an improvement in the representation of air temperatures and the net energy flux over these surfaces (Cullather et al. 2014).

\section{3) ERA-INTERIM}

ERA-Interim (Dee et al. $2011 ; 0.75^{\circ} \times 0.75^{\circ} \times 37$ levels) is developed by ECMWF. ERA-Interim replaced the previous reanalysis dataset from ECMWF, ERA-40. Between ERA-40 and ERA-Interim, many changes have been implemented to correct some problems encountered in the previous version of the reanalysis. Major changes have occurred on the convective and boundary layer cloud schemes. For example, the convective scheme can now be triggered at night, which increases its atmospheric stability and therefore creates less precipitation (Dee et al. 2011). Thanks to a new moist boundary layer scheme, the underestimation of stratocumulus clouds has decreased because of changes in the inversion strength and height (Köhler et al. 2011). Convection, vertical motion, radiative heating, and turbulence are connected to cloud generation via the prognostic cloud scheme (Jakob 1999). The Rapid Radiative Transfer Model computes radiation (Mlawer et al. 1997).

\section{4) JRA-55}

The Japan Meteorological Agency (JMA) has recently developed its second reanalysis dataset after JRA-25: JRA-55 (Kobayashi et al. 2014, 2015; 0.56 $\times$ $0.56^{\circ} \times 60$ levels). The new configuration of the reanalysis is produced using the TL319 version of JMA's operational data assimilation system. JRA-55 starts in
1958, when regular radiosondes started getting a global coverage. JRA-55 also uses several newly available datasets and improved past observations. Since the JRA25 data assimilation system, JMA has revised the longwave radiation scheme, implemented a four-dimensional variational analysis and a variational bias correction, and increased the horizontal resolution from 110 to $55 \mathrm{~km}$. The cumulus parameterization is the same as JRA-25, which used the Arakawa-Schubert mass flux (Kobayashi et al. 2014), but JRA-55 employs a convective triggering mechanism from Xie and Zhang (2000). The cloud radiation scheme uses a maximum random overlap method from Räisänen (1998). The shortwave radiation scheme is based on Joseph et al. (1976) and Coakley et al. (1983), while the longwave radiation scheme is based on Chou et al. (2001). JRA-55 shows improvements, compared to JRA-25 (Kobayashi et al. 2015), removing several deficiencies appearing in the first Japanese reanalysis. For example, the modifications introduced in the new datasets highly diminished a cold bias in the lower troposphere and a dry bias in the Amazon. However, first evaluations of JRA-55 revealed problems such as a warm bias in the upper troposphere, large upward imbalance in the global mean net energy fluxes at the top of the atmosphere, and excessive precipitation over the tropics.

To objectively compare the different reanalysis datasets with each other and with the observations, all the datasets are interpolated to a common $2.5^{\circ} \times 2.5^{\circ}$ grid, and we use monthly temporal resolution. The time period of all reanalyses used is January 2007 to December 2010 to match the observation time period.

\section{c. Cloud impact parameters}

The cloud impact parameters can be divided into two categories: the cloud radiative parameters $\left(G_{\mathrm{cld}}, A_{\text {cld }}\right.$, and $N$ ) and the energy and water coupling parameters $\left(R_{c}\right.$ and $\left.R_{h}\right)$. The distinctive categories are due to their difference in definitions. The former is based on radiative fluxes only, while the energy and water coupling parameters are coupled with the environment via latent heating.

\section{1) Cloud RAdiative PARAMETERS}

$G_{\text {cld }}$ (the cloud greenhouse effect) and $A_{\text {cld }}$ (the cloud albedo effect) encapsulate the competing effects of clouds on the atmosphere. The cloud greenhouse effect $G_{\text {cld }}$ is defined as the cloud impact on outgoing longwave radiation expressed as a fraction of surface emission. Following the clear-sky greenhouse parameter $G$ introduced in Stephens and Greenwald (1991), we define

$$
G_{\mathrm{cld}}=-\frac{F_{\mathrm{LW}, \mathrm{TOA}, \mathrm{all}}^{\uparrow}-F_{\mathrm{LW}, \mathrm{TOA}, \mathrm{clear}}^{\uparrow}}{F_{\mathrm{LW}, \mathrm{SFC}}^{\uparrow}},
$$


where $F_{\mathrm{LW}, \mathrm{TOA}}^{\uparrow}$ and $F_{\mathrm{LW}, \mathrm{SFC}}^{\uparrow}$ represent the upwelling LW fluxes at the TOA and SFC, respectively. Subscripts "clear" and "all" correspond to clear-sky and all-sky conditions, respectively. For all datasets, clear sky includes both cloud-free conditions and situations where clouds were removed for radiative transfer calculations. These notations are the same for the equations of the five parameters. Like $G, G_{\text {cld }}$ provides a measure of the atmospheric greenhouse effect but isolates cloud impacts. $G_{\text {cld }}$ vanishes in the absence of any cloudiness and goes to 1 in the limit of a perfect greenhouse. Larger values of $G_{\text {cld }}$ indicate a higher greenhouse effect and therefore a warming of the atmosphere through the clouds.

Cloud effects on shortwave radiation are characterized by their impact on regional albedo. The cloud albedo effect $A_{\text {cld }}$ is defined as the difference in reflectivity of the planet resulting from clouds:

$$
A_{\text {cld }}=\frac{F_{\mathrm{SW}, \mathrm{TOA}, \mathrm{all}}^{\uparrow}-F_{\mathrm{SW}, \mathrm{TOA}, \mathrm{clear}}^{\uparrow}}{F_{\mathrm{SW}, \mathrm{TOA}}^{\downarrow}},
$$

where SW is used for shortwave fluxes, and $\downarrow$ represents downwelling radiation; $A_{\text {cld }}$ is closely related to cloud forcing, but includes a normalization by incoming solar radiation to partially remove the dependence on the time of day and latitude. Larger values of $A_{\text {cld }}$ indicate a higher albedo effect and therefore a cooling of the atmosphere through the clouds. $A_{\text {cld }}$ reflects the albedo effect of clouds, so we expect this parameter to be sensitive especially to bright clouds.

The ratio $N$ provides a dimensionless measure of the relative strengths of cloud albedo and greenhouse effects, or the ratio of cloud shortwave forcing (CSWF) to the corresponding cloud longwave forcing (CLWF) at the top of the atmosphere:

$$
\begin{aligned}
N & =\frac{\mathrm{CSWF}}{\mathrm{CLWF}} \\
& =-\frac{\left(F_{\mathrm{SW}, \mathrm{TOA}}^{\downarrow}-F_{\mathrm{SW}, \mathrm{TOA}}^{\uparrow}\right)_{\mathrm{all}}-\left(F_{\mathrm{SW}, \mathrm{TOA}}^{\downarrow}-F_{\mathrm{SW}, \mathrm{TOA}}^{\uparrow}\right)_{\text {clear }}}{F_{\mathrm{LW}, \mathrm{TOA}, \mathrm{all}}^{\uparrow}-F_{\mathrm{LW}, \mathrm{TOA}, \mathrm{clear}}^{\uparrow}}
\end{aligned}
$$

where for low clouds, $N>1$, while $N<1$ for thin high clouds. In other words, $N$ values greater than (less than) 1 , indicate a net cooling (heating) at the top of the atmosphere.

\section{2) ENERGY AND WATER COUPLING PARAMETERS}

Together, $G_{\text {cld }}, A_{\text {cld }}$, and $N$ provide a robust characterization of cloud radiative effects that minimize the dependency on background atmospheric state fields. However, circulations respond to the balance between precipitating clouds heating or cooling the environment radiatively and the heat from precipitation generation, so additional parameters characterizing precipitating clouds are necessary. Following the cloud feedback studies of Bretherton and Sobel (2002) and Sobel and Gildor (2003), L'Ecuyer et al. (2006) explored two parameters that characterize the degree to which a precipitating cloud cools the surface or heats the atmosphere, respectively. $R_{c}\left(R_{h}\right)$ is a measure of the cooling (heating) ratio between radiation and precipitation since the majority of the cooling effect of clouds is realized at the earth's surface. The former, referred to as the surface radiative cooling efficiency $R_{c}$, is defined as

$$
R_{c}=-\frac{F_{\mathrm{SW}, \mathrm{SFC}, \mathrm{all}}^{\downarrow}-F_{\mathrm{SW}, \mathrm{SFC}, \mathrm{clear}}^{\downarrow}}{\mathrm{LH}},
$$

where $F_{\mathrm{SW}, \mathrm{SFC}}$ is the shortwave radiation reaching the surface evaluated in clear-sky and all-sky conditions. LH is the latent heating in the column that forms the precipitation reaching the surface, defined through a conversion from precipitation flux:

$$
\mathrm{LH}=\rho \times q_{v} \times \mathrm{PR},
$$

where $\rho$ is the density of water, $q_{v}$ is latent heat of vaporization for water, and $P R$ is the average surface precipitation rate. Similarly, the radiative heating efficiency describes a cloud's ability to heat the atmosphere per unit LH:

$$
R_{h}=\frac{\left(\Delta F_{\mathrm{LW}}-\Delta F_{\mathrm{SW}}\right)_{\mathrm{all}}-\left(\Delta F_{\mathrm{LW}}-\Delta F_{\mathrm{SW}}\right)_{\text {clear }}}{\mathrm{LH}},
$$

where $\Delta F_{\mathrm{LW}}=F_{\mathrm{LW}, \mathrm{SFC}}^{\uparrow}-F_{\mathrm{LW}, \mathrm{SFC}}^{\downarrow}-F_{\mathrm{LW}, \mathrm{TOA}}^{\uparrow}$ and $\Delta F_{\mathrm{SW}}=$ $F_{\mathrm{SW}, \mathrm{TOA}}^{\downarrow}-F_{\mathrm{SW}, \mathrm{SFC}}^{\uparrow}-F_{\mathrm{SW}, \mathrm{SFC}}^{\downarrow}-F_{\mathrm{SW}, \mathrm{TOA}}^{\uparrow}$ are the LW and SW atmospheric radiative flux divergences, respectively. $R_{h}$ is the only parameter that can provide both positive and negative values. Together, these five cloud impact parameters provide summarization of not only the impact of clouds on radiation balances, but also the relative radiation impact, compared to precipitation generation heating.

\section{Observed distributions}

Figure 2 presents spatial maps of the CIPs for CloudSat observations. Again, the cloud radiative parameters $G_{\text {cld }}, A_{\text {cld }}$, and $N$ and the energy and water cycle coupling parameters $R_{c}$ and $R_{h}$ are averaged over the time period 2007-10.

\section{a. Cloud radiative parameters}

Figure 2a shows the observed spatial distribution of the greenhouse effects of clouds $G_{\text {cld }}$. High values of 
(a) Gcld CloudSat

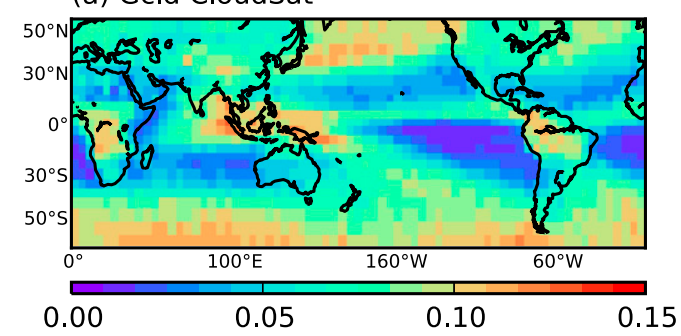

(c) $\mathrm{N}$ CloudSat

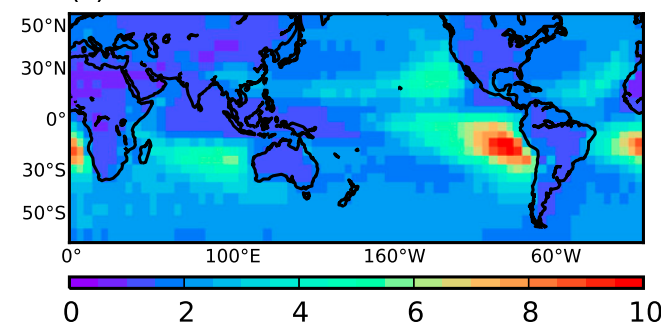

(e) Rc CloudSat

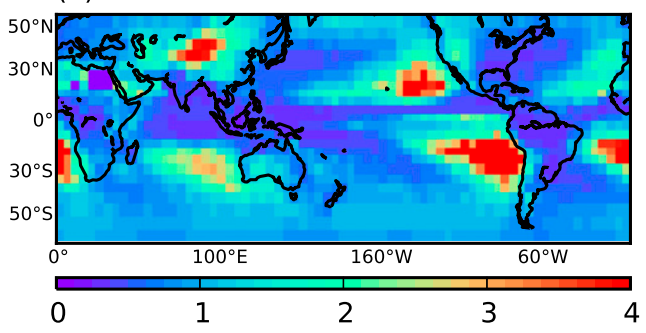

$G_{\text {cld }}$ mean a warming of the atmosphere through the clouds. Patterns of $G_{\text {cld }}$ are highly correlated with the presence of high clouds that tend to appear over the tropics and at high latitudes. The highest observed values of $G_{\text {cld }}$, and therefore warming of the atmosphere, appear over the tropical continent, especially over parts of South Africa, the Maritime Continent, and South America. Indeed, the tropics tend to have a lot of convective clouds (cumulus), which are known for their ability to trap longwave radiation. Over the $45^{\circ} \mathrm{N}$ and $45^{\circ} \mathrm{S}$ bands, regions with high values of $G_{\text {cld }}$ are present over the Pacific and Atlantic Oceans. However, these values are lower than over the tropics. At these latitudes, high values of $G_{\text {cld }}$ are due to the persistent presence of stratus clouds. Because stratus and convective clouds are high and, therefore, cold, the energy they radiate to space is lower than it would be in clearsky conditions, explaining their large greenhouse forcing.

Figure $2 \mathrm{~b}$ shows the observed spatial distribution of the albedo effect of clouds $A_{\text {cld }}$. High values of $A_{\text {cld }}$ indicate a cooling of the atmosphere through the clouds. The effect of clouds on the atmosphere is high around the equator and at high latitudes for both the greenhouse (warming) and albedo (cooling) effects, (b) Acld CloudSat

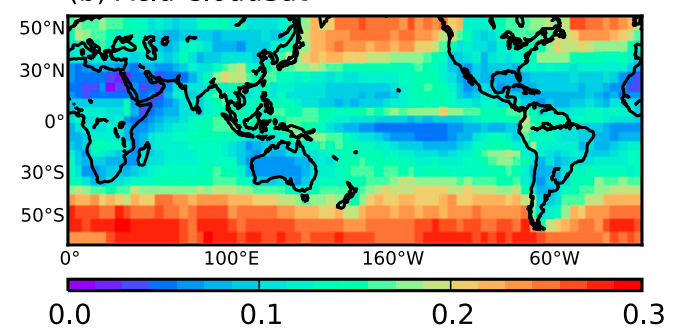

(d) Rh CloudSat

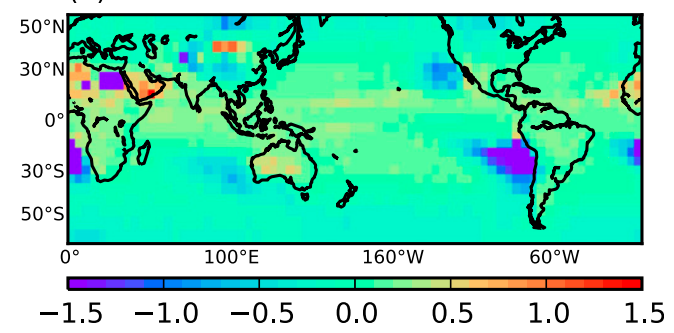

FIG. 2. Mean spatial distribution of the CIPs: (a) $G_{\text {cld }}$, (b) $A_{\text {cld }}$, (c) $N$, (d) $R_{h}$, and (e) $R_{c}$ for the satellite observations CloudSat from 2007 to 2010.

with different amplitudes. This is understandable, as reflective stratus dominate in the high latitudes, and deep convection with high-altitude outflow is present along the equator. Stratus clouds are also known for their high values in albedo due to their composition, which tends to be high in water drops and supercooled water. In the Southern Hemisphere, over $45^{\circ} \mathrm{S}$, high values of $A_{\text {cld }}$ also appear over the Indian, Pacific, and Atlantic Oceans for the same reasons as the Northern Hemisphere. Again, similar to $G_{\text {cld }}$, moderate to high values of $A_{\text {cld }}$ also coincide with the band of deep convective clouds in the intertropical convergence zone (ITCZ) that reflect a lot of the solar energy back to space. Contrarily to $G_{\text {cld }}$, high values of $A_{\text {cld }}$ appear on the eastern side of the oceans, where marine stratocumulus persist over the dark ocean background. Stratocumulus are low, optically thick clouds that reflect much of their solar energy back to space, explaining their high values in $A_{\text {cld }}$. On the other hand, because stratocumulus are low clouds, they have a similar temperature to the surface, and they radiate at nearly the same intensity as the surface, explaining their low greenhouse effect (cf. Fig. 2a).

It is evident from Figs. $2 \mathrm{a}$ and $2 \mathrm{~b}$ that differences in the strength of the cloud albedo (SW radiation) and 
greenhouse (LW radiation) effects exhibit regional patterns that closely reflect the large-scale circulations. This signature is also clear in Fig. 2c, which presents the observed spatial distribution of $N$, the dimensionless ratio of cloud SW to LW forcing. When $N$ is above (under) 1, clouds are cooling (warming) the atmosphere. Deep convection over the tropics characterized by cold, bright cloud tops exhibits values of $N$ near 1 (Kiehl 1994) because of the near-compensating effects between the shortwave reflection and the longwave heating. The same compensating effect also applies to the highlatitude stratus clouds. Therefore, the highest values of $N$ appear in subsidence regions of the subtropics, where bright marine stratocumulus clouds near the surface are dominant. The high values of $N$ in these regions mean that these clouds provide a net cooling through the atmosphere, while other types of clouds, such as tropical cumulus clouds, tend to have a neutral impact on the atmosphere.

\section{b. Energy and water cycle coupling parameters}

Figures $2 \mathrm{~d}$ and $2 \mathrm{e}$ present the spatial distribution of the atmospheric heating from precipitating clouds $R_{h}$ and the surface cooling from precipitating clouds $R_{c}$, respectively, for the CloudSat satellite observations. Positive (negative) values of $R_{h}$ indicate a warming (cooling) of the atmosphere. Values of $R_{c}$ above (under) 1 indicate a cooling (warming) of the surface through the clouds. The highest values of $R_{h}$ and $R_{c}$ (positive or negative) appear over the subtropics, related to the presence of stratocumulus at these latitudes. Marine stratocumulus cools the surface $\left(R_{c}\right)$ and the atmosphere $\left(R_{h}\right)$ through the clouds. It also seems, by the higher and more widely spread values of $R_{c}$, that the marine stratocumulus clouds more efficiently cool the surface than the atmosphere, which is coherent with their shallow-cloud structure. Over the rest of the domain, the parameters present lower values in both $R_{h}$ and $R_{c}$, which does not mean that these areas are not important. For example, we hypothesize that a change in $R_{c}$ or $R_{h}$ of 0.1 to 0.2 over the west Pacific Ocean could have significant influence on the propagation of the Madden-Julian oscillation (MJO). These variations could affect the turbulent fluxes from the surface or alter the availability of tropospheric moistening, both thought to play a role in the MJO (Hsu and Li 2012; Del Genio et al. 2012). If reanalyses or models do not capture this sensitivity correctly, they might not properly capture the MJO.

By definition, $R_{h}$ and $R_{c}$ depend not only on cloud cover, but also on precipitation through latent heating. Providing measures of the efficiencies in which precipitating clouds modulate shortwave and longwave radiation is necessary for understanding both low and high cloud feedbacks. For example, $R_{h}$ is a good proxy for processes like convective aggregation. The tendency of convection to self-aggregate has long been documented and related to the occurrence of extreme rainfall events (e.g., Bretherton et al. 2005; Nolan et al. 2007; Khairoutdinov and Emanuel 2013). Several studies also showed that the degree of aggregation of a system exerts a strong feedback on the mean atmospheric state. Simulations find that atmospheres where convection is more aggregated are drier, clearer, and more efficient at radiating heat to space (Bretherton et al. 2005; Tobin et al. 2012; Bony et al. 2015). Cloud-resolving simulations also showed that self-aggregation might increase with temperature, which could have very important implications for future climate scenarios. Among others, Bony et al. (2015) and Holloway et al. (2017) emphasize the need for a better understanding of convective aggregation and metrics for identifying its prevalence in observations and representation in global models. The parameter $R_{h}$ could serve as such a metric by measuring the increase in precipitation intensity, compared to the decrease in radiation effects. Stein et al. (2017) examined the relationship between cloud vertical structure and aggregation, showing that cirrus, congestus, and midlevel clouds do not display a consistent relationship with the degree of aggregation, while low-level clouds do. Figure $2 \mathrm{~d}$ confirms this result by showing higher values of $R_{h}$ where marine stratocumulus (low-level clouds) dominate.

L'Ecuyer et al. (2006) used the radiative efficiencies to show evidence of clouds' feedback pathways associated with ENSO in the Pacific. They demonstrated that clouds in the east Pacific heat the atmosphere (higher $R_{h}$ ) more efficiently and cool the surface (lower $R_{c}$ ) less efficiently with increasing SST, suggesting that changes in cloud characteristics may reinforce changes in the Walker circulation during El Niño events. Furthermore, $R_{c}$ characterizes the efficiency with which a low cloud cools the surface per unit rainfall. This relationship is, for example, central to aerosol impacts on warm cloud lifetime (Wang et al. 2012), a process that is not well represented in climate models but has important implications for the global energy budget. This may stem, in part, from biases in warm cloud parameterizations that result in both insufficient warm cloud cover (Kay et al. 2012) and too-frequent drizzle (Stephens 2005), the net impacts of which are concisely captured by $R_{c}$. A better representation of this particular process is crucial for increasing the confidence in climate projections.

In Fig. 2, however, the CIPs have been derived at a monthly time scale and interpolated over a $2.5^{\circ} \times 2.5^{\circ}$ grid. As such, these results do not speak to specific 

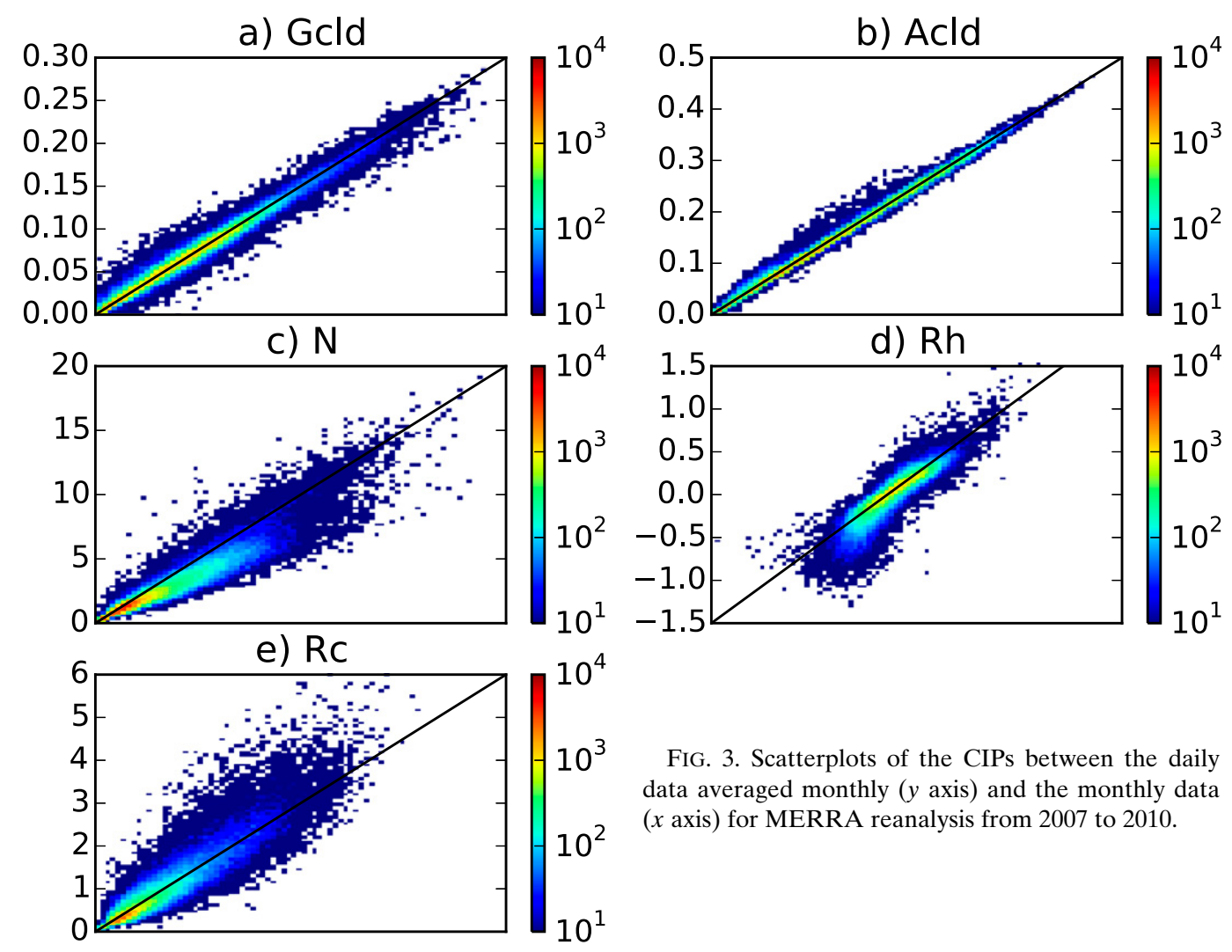

FIG. 3. Scatterplots of the CIPs between the daily data averaged monthly ( $y$ axis) and the monthly data ( $x$ axis) for MERRA reanalysis from 2007 to 2010.

processes in the traditional sense (i.e., the process-level interactions between the cloud system and its local environment that occur on short time scales and high spatial resolutions). On the scales examined here, the CIPs represent the aggregate impact of these underlying cloud and precipitation processes in a statistical sense, providing a metric more suited to examining net impacts of the way these processes are parameterized. This is demonstrated in Fig. 3, which shows scatterplots for the CIPs between the daily data averaged monthly and the monthly data for MERRA reanalysis as an example. The results are very similar for the other reanalyses, and this general relationship holds on even shorter time scales of hourly (not shown). Clearly, daily and monthly mean values of the first two parameters $\left(G_{\text {cld }}\right.$ and $\left.A_{\text {cld }}\right)$ exhibit strong correlations. The other three parameters $\left(N, R_{h}\right.$, and $\left.R_{c}\right)$ also exhibit a strong connection between the monthly and daily scales, but the points are more scattered, illustrating how the variability induced by processes that occur on shorter time scales aggregate to yield the monthly scale responses examined here. Daily values ultimately aggregate up to monthly scales but with more noise, especially in $N, R_{h}$, and $R_{c}$, owing to the higher dynamic range of the ratios on shorter scales. The characteristics of some of the CIPs $\left(R_{c}\right.$ and $\left.R_{h}\right)$

on the shorter time scales representative of processes are considered in more details by Sun et al. (2018, unpublished manuscript).

\section{Representation of the CIPs in reanalyses}

\section{a. Cloud radiative parameters}

Figure 4 presents the mean spatial distribution of the cloud greenhouse effect, $G_{\text {cld }}$ for the reanalyses (left column) as well as their biases relative to CloudSat (right column). Black hatches indicate where the differences between CloudSat and the reanalyses are significant at the $99 \%$ level. The significant test used here is an unequal variance $t$ test. As explained in section 3, high values of $G_{\text {cld }}$ are indicative of a warming of the atmosphere through clouds and are usually related to high clouds, which are frequently observed over the tropics and high latitudes (over $45^{\circ} \mathrm{N}$ and $45^{\circ} \mathrm{S}$ ). Although the reanalyses tend to agree in the representation of the spatial patterns of $G_{\text {cld }}$, large significant differences in amplitude appear between the reanalyses and satellite observations. Both versions of MERRA exhibit a significant positive bias in $G_{\text {cld }}$ over the tropics, and this bias has increased in MERRA-2 (Fig. 4). This 
(a) Gcld MERRA2

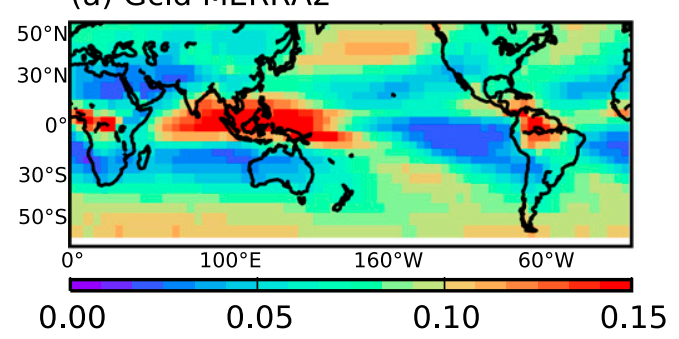

(c) Gcld MERRA

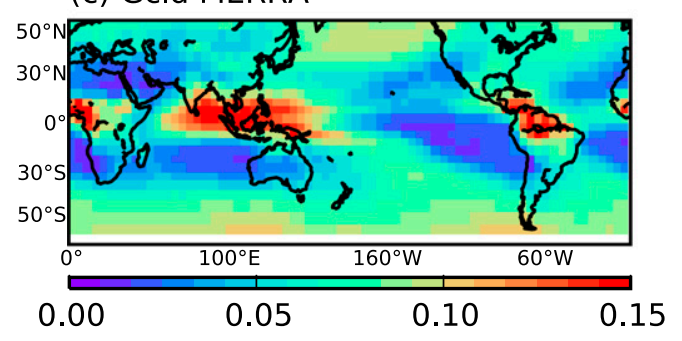

(e) Gcld ERAI

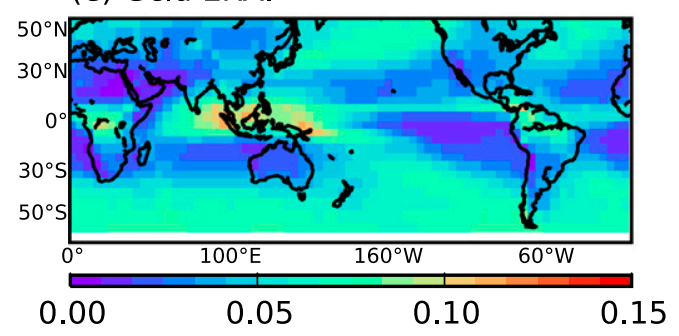

(g) Gcld JRA55

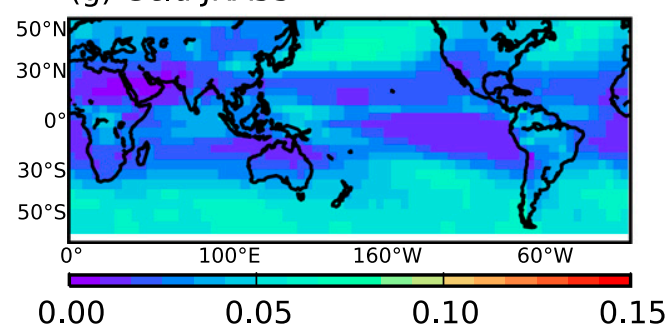

(b) MERRA2 - CloudSat

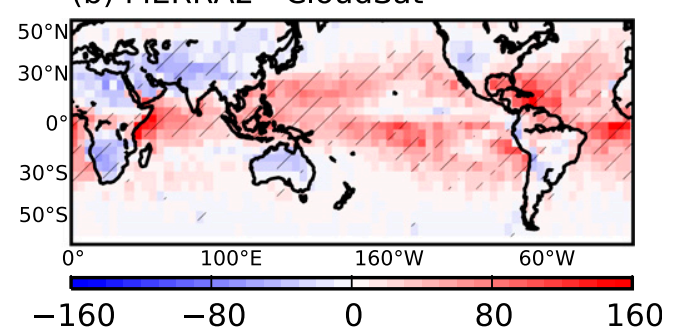

(d) MERRA - CloudSat

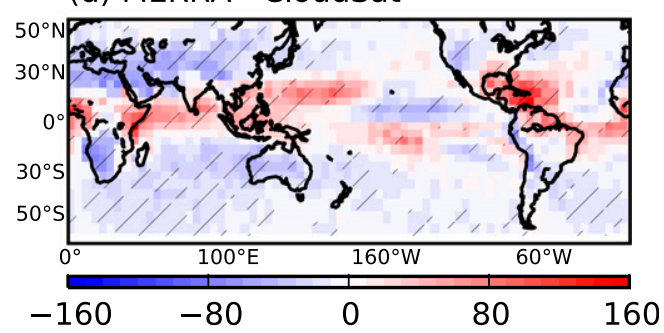

(f) ERAI - CloudSat

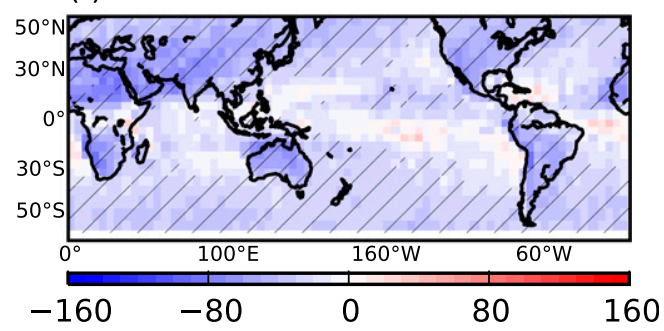

(h) JRA55 - CloudSat

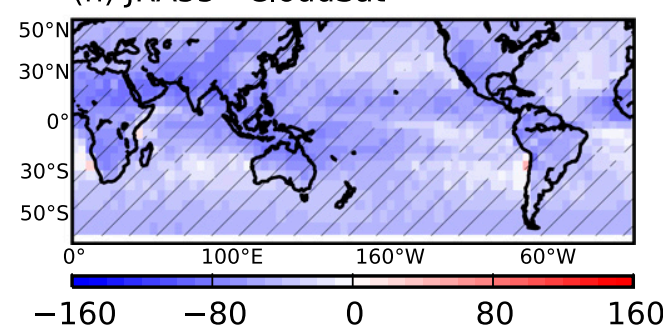

FIG. 4. Mean spatial distribution of $G_{\text {cld }}$ for the (left) reanalyses for (a) MERRA-2, (c) MERRA, (e) ERAInterim, and (g) JRA-55; and the (right) bias (\%) for (b) MERRA-2 - CloudSat, (d) MERRA - CloudSat, (f) ERA-Interim - CloudSat, and (h) JRA-55 - CloudSat from 2007 to 2010. Black hatches indicate where the differences are significant at the $99 \%$ level.

means that both MERRA reanalyses tend to warm the atmosphere too much over the tropics. The MERRA reanalyses tend to simulate a total cloud fraction too high over the tropics (Dolinar et al. 2016). One could expect the cloud fraction in MERRA-2 to be even higher to explain the higher bias in $G_{\text {cld }}$, compared to MERRA. Interestingly, the comparison of total cloud fraction between MERRA and MERRA-2 (not shown) shows that MERRA-2 has improved, compared to MERRA. The total cloud fraction over the tropics is lower in the most recent dataset. This suggests that the reason for the higher bias in MERRA-2, compared to
MERRA, does not result from errors in cloud amount but rather changes in morphology or height in the most recent dataset. Clouds in MERRA-2 may become too thick or cold relative to the original MERRA. This emphasizes the limitation of comparing cloud fractions without also examining the resulting impacts. At high latitudes (over $45^{\circ} \mathrm{N}$ and $45^{\circ} \mathrm{S}$ ), MERRA-2 improves the representation of $G_{\text {cld }}$, compared to MERRA, as the significant underestimate in $G_{\text {cld }}$ in MERRA disappeared in the new version of the reanalysis. In contrast, ERA-Interim captures the cloud greenhouse effect over the tropics well, with only some significant 
(a) Acld MERRA2

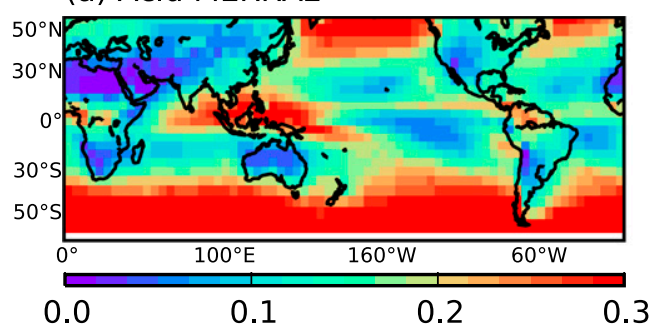

(c) Acld MERRA

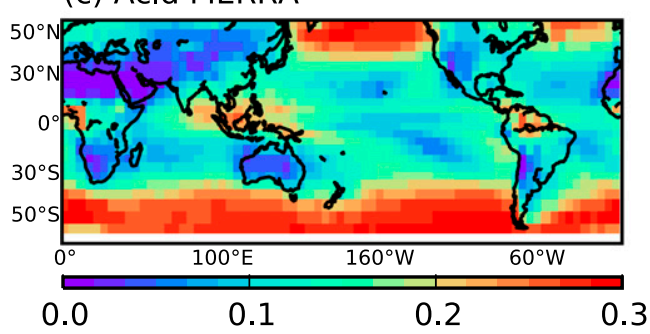

(e) Acld ERAI

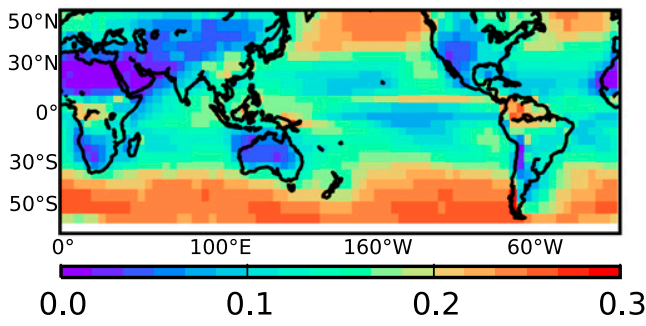

(g) Acld JRA55

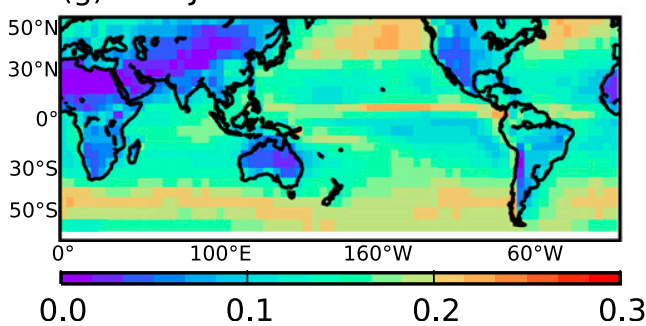

(b) MERRA2 - CloudSat

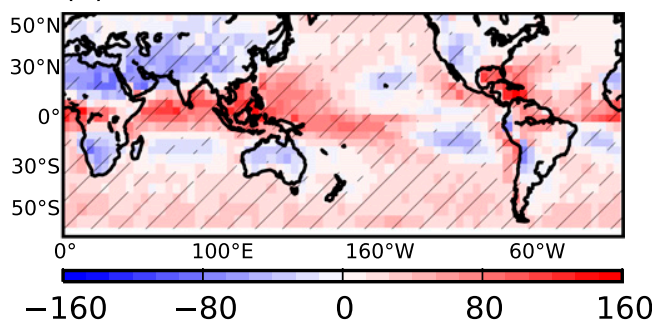

(d) MERRA - CloudSat

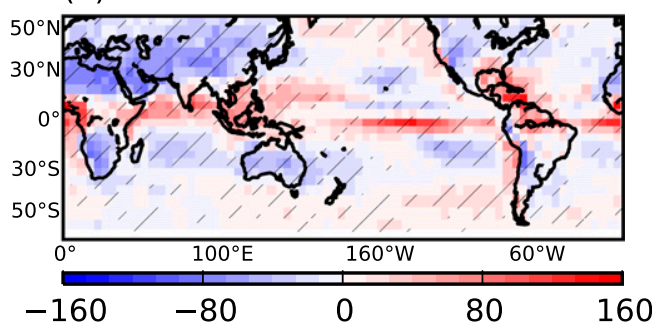

(f) ERAI - CloudSat

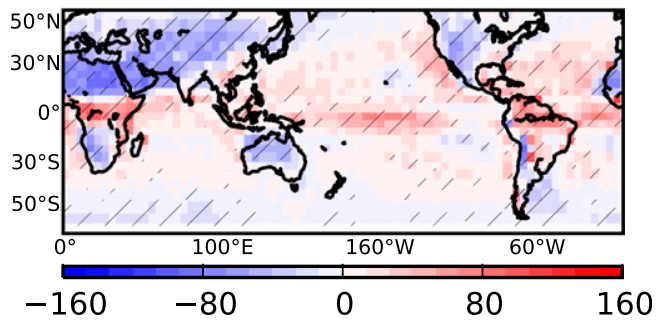

(h) JRA55 - CloudSat

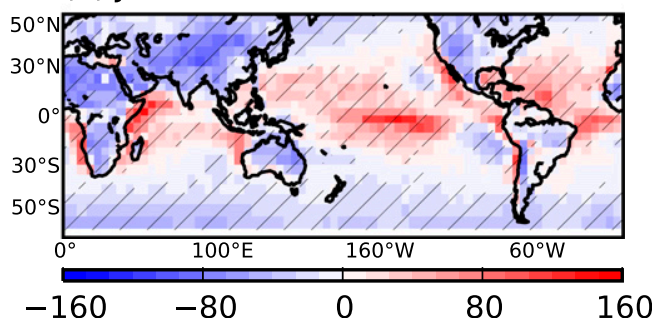

FIG. 5. As in Fig. 4, but for $A_{\text {cld }}$.

biases over the tropical continents. This is coherent with its ability to represent the cloud fraction over the tropics shown by Dolinar et al. (2016). On the other hand, like MERRA, ERA-Interim underestimates $G_{\text {cld }}$ at high latitudes, cooling the atmosphere through clouds too much. The bias in ERA-Interim is more spread than in MERRA, covering all lands and oceans at high latitudes in both hemispheres. JRA-55 exhibits the largest greenhouse effect biases of the four reanalyses. JRA-55 underestimates the cloud greenhouse effect globally, particularly dramatically over the tropics.

Figure 5 presents the mean spatial distribution (left column) and biases (right column) of $A_{\text {cld }}$ for each reanalysis dataset. The reanalyses tend to reproduce the general pattern of $A_{\mathrm{cld}}$ with high values present over the tropics, high altitudes, and over the subtropics on the east side of the oceans, as observed with CloudSat (cf. Fig. 2). However, the reanalyses exhibit some significant differences, compared to the satellite observations. In general, ERA-Interim and MERRA are the closest to CloudSat, showing lower, but significant, biases, compared to MERRA-2 and JRA-55. However, all the reanalyses significantly overestimate the albedo effect over the tropics, meaning that they tend to cool the tropics too much through clouds. This result is coherent with previous studies that demonstrated the large biases in tropical rainfall in the reanalyses (Kim and Alexander 2013; Dolinar et al. 2016). One striking feature in Fig. 6 is 
(a) N MERRA2

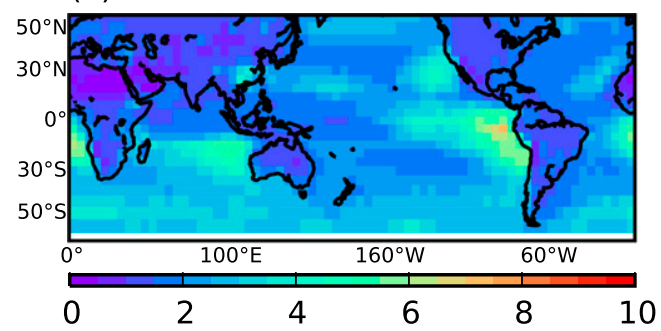

(c) N MERRA

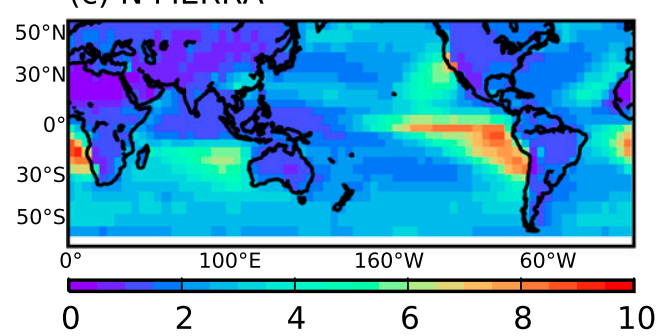

(e) N ERAI

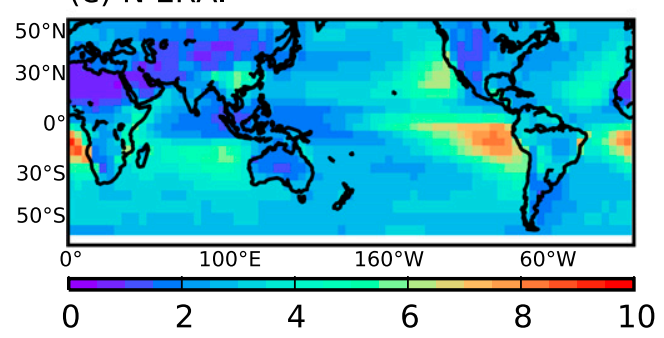

(g) N JRA55

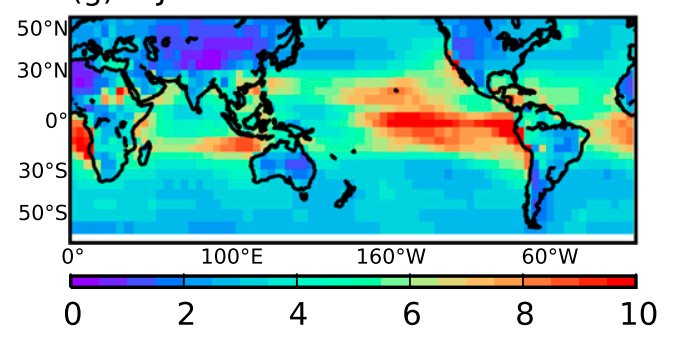

(b) MERRA2 - CloudSat

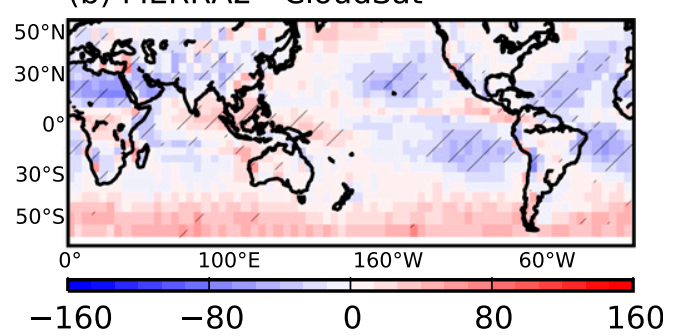

(d) MERRA - CloudSat

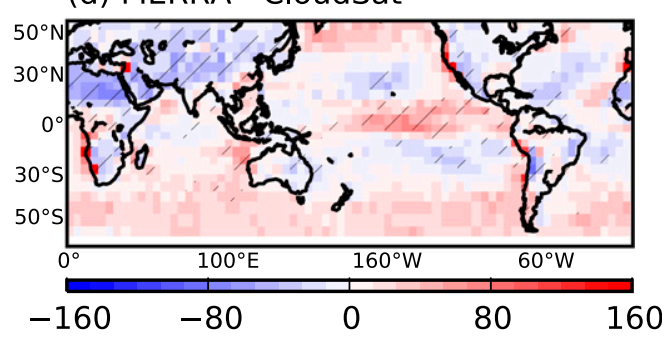

(f) ERAl - CloudSat

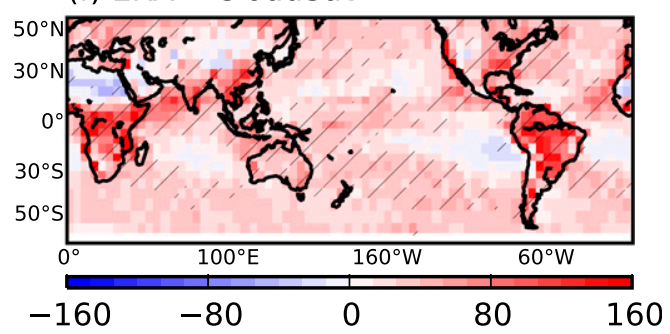

(h) JRA55 - CloudSat

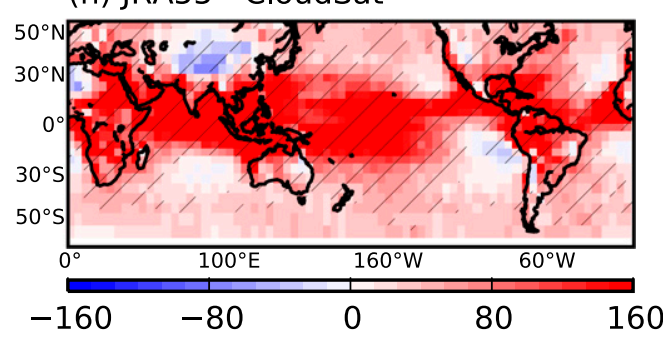

FIG. 6. As in Fig. 4, but for $N$.

the positive bias of MERRA-2, compared to MERRA, over the tropics. In this region, MERRA-2 presents a higher and larger bias, compared to MERRA. This might be indicative of a problem in the representation of tropical outflow or perhaps even the MJO in MERRA's datasets. This would be consistent with Bosilovich et al. (2015), who showed that MERRA-2 has a stronger MJO signal than GPCP. Except ERA-Interim, all the reanalyses tend to underestimate the albedo effect where marine stratocumulus forms. Another interesting difference between the different reanalyses appears for JRA-55. The albedo effect is significantly underestimated at high latitudes where stratus dominates, particularly in the Southern Hemisphere. All the reanalyses show negative biases in $A_{\text {cld }}$ over the continents (Fig. 5), but the Japanese reanalysis is the only one to expand them over the oceans. Furthermore, Fig. 5 shows that the magnitude of the albedo effect over these regions is small, so subtle differences could result in high percent biases.

The mean spatial distribution of $N$ in the reanalyses (left column) and the biases (right column) are presented in Fig. 6. As in the CloudSat observations over the tropics and at high latitudes, the competing strong albedo (SW radiation) and greenhouse (LW radiation) effects of deep convective clouds results in $N$ approaching 1 . With the exception of JRA-55, tropical biases in $G_{\text {cld }}$ and $A_{\text {cld }}$ in the reanalyses largely compensate for one another, yielding a relatively low bias in $N$. For 
JRA-55, the significant overestimate in $N$ relative to CloudSat is related to the overestimate in cloud albedo effect (cf. Fig. 5), suggesting that deep convection exerts too much net cooling in the tropics in this reanalysis. For all reanalyses, the highest values of $N$ appear in subsidence regions of the subtropics where bright stratocumulus clouds near the surface appear, and therefore SW radiation is dominant over LW radiation, as shown in Figs. 3 and 4. All four reanalyses present similar significant dipole biases in the marine stratocumulus regions, underestimating $N$ in the subtropics and overestimating it in the tropics. This bias can be due to different factors. Over the region where stratocumulus prevail, several studies showed that reanalyses tend to have difficulty accurately representing cloud cover. Duynkerke and Teixeira (2001) showed that ERA-15 (Gibson et al. 1997) strongly underestimates the stratocumulus cloud cover and liquid water path. They postulate that this is due to the insufficient vertical resolution of the dataset, which does not allow the moisture to mix deep enough into the cloud layer. However, Stevens et al. (2007) showed that the increase of vertical resolution in the next version of the reanalysis, ERA-40 (Uppala et al. 2005), did not prevent biases in this region. They argued that these biases could be a combination of insufficient vertical resolution and the need for better accounting for moist thermodynamics and a better representation of entrainment rates. In addition, Teixeira et al. (2011) showed that models can have difficulties in capturing the shift in cloud frequency from stratocumulus in the subtropics to deep convection in the tropics, leading to biases in the tropical regions. Greater insights into the causes of the biases in subtropical stratocumulus regions can be gleaned from the radiative efficiency parameters $R_{h}$ and $R_{c}$.

\section{b. Energy and water cycle coupling parameters}

The strong coupling of the energy and water cycles in the climate system warrants new efforts to analyze metrics that more deeply probe the integrated radiative and precipitation influences of cloud systems. Figures 7 and 8 present the annual mean distributions of $R_{h}$ and $R_{c}$, respectively, for each reanalysis (left panels) and their biases relative to satellite observations (right panels). To help in the interpretation of the biases for $R_{h}$, the only parameter that can present both positive and negative values, white dots have been added in Fig. 8 to show where CloudSat and each reanalysis shows a different sign. Like the satellite products, marine stratocumulus in the eastern tropical oceans exhibit the largest atmospheric heating $\left(R_{h}\right)$ and surface cooling $\left(R_{c}\right)$ owing to their light precipitation yields. Even though the absolute values of both parameters are small over the rest of the domain, like the convective regions, large significant fractional errors exist for each reanalysis in these areas. These errors can have significant implications in terms of energy balance and cloud feedbacks.

Globally, all reanalyses are very strongly biased with respect to observations. The highest biases appear for $R_{h}$, and it is interesting that the biases are very different among the reanalyses. MERRA reanalyses tend to overestimate atmospheric heating from precipitating clouds over the tropics and underestimate it over the rest of the domain, while ERA-Interim shows the opposite behavior. Finally, it is interesting to note that JRA-55 shows a very different behavior, compared to the other reanalyses; JRA-55 tends to underestimate $R_{h}$ over the entire domain. Based on the analyses of the first three parameters, it is plausible to think that this difference comes from a global underestimate in LW radiation at the top of the atmosphere. Figure 4 clearly showed a strong and global underestimate in $G_{\text {cld }}$ for JRA-55, which did not appear for the other reanalyses. Instead, for $R_{c}$, the biases are very similar among the reanalyses. All of the reanalyses underestimate $R_{c}$ in the region of the marine stratocumulus, indicating that clouds tend to cool the surface too much. On the northern side of these regions, a positive bias is present for $R_{c}$. Like the other reanalyses, JRA-55 has a strong bias in the region of transition between subtropics and the tropics, but it also shows a strong bias in the background. JRA-55 globally underestimates the surface cooling from precipitating clouds. This bias could be the result of a combination of biases, with an underestimate in albedo effect at high latitudes (cf. Fig. 5) and an overestimate in precipitation over the tropics (not shown). The biases over the subtropical regions will be further explored in the next section.

\section{Natural variability and relationship to large-scale circulations}

The broad global discussions in sections 3 and 4 emphasize that each parameter exhibits unique sensitivities to different cloud regimes. To gain deeper insights into what we can learn from the CIPs, the response of selected parameters is first examined looking at the seasonal cycle of the convection over the Indo-Pacific warm pool and the marine stratocumulus over the northeast Pacific Ocean. Then, to further generalize these findings, we explore the relationship between the CIPs and 500-hPa pressure velocity, a proxy for the large-scale overturning circulation.

\section{a. Seasonal cycle of the Indo-Pacific warm pool}

The Indo-Pacific warm pool is a very singular region of the world where surface temperature is permanently 
(a) Rh MERRA2

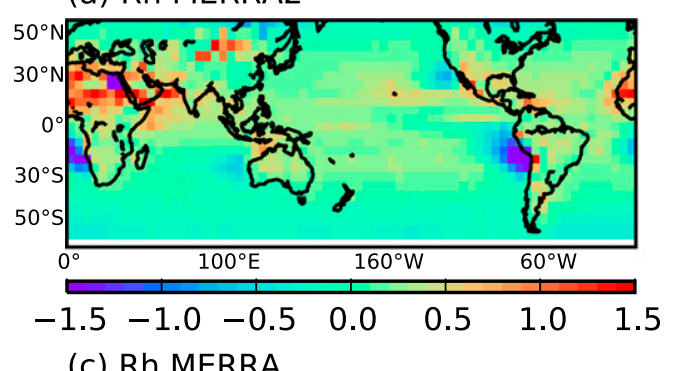

(c) Rh MERRA

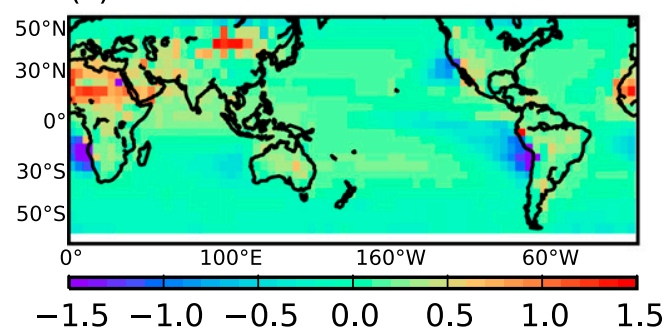

(e) Rh ERAI

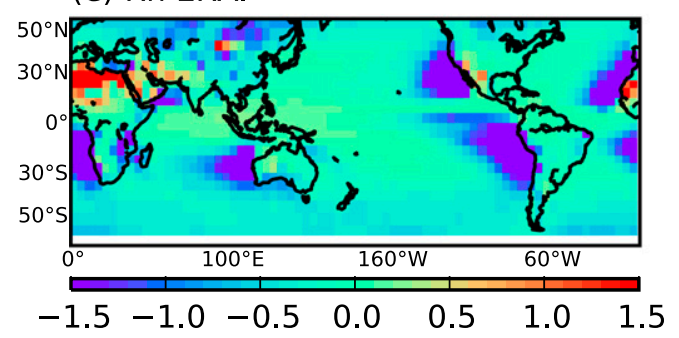

(g) Rh JRA55

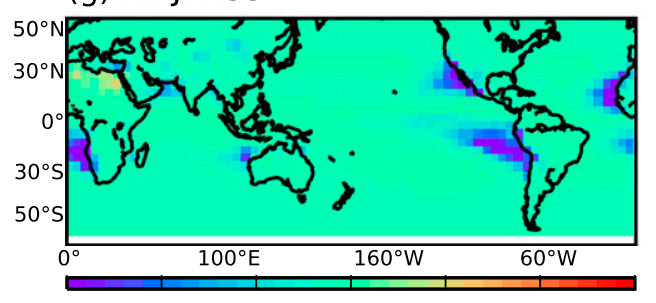

(b) MERRA2 - CloudSat

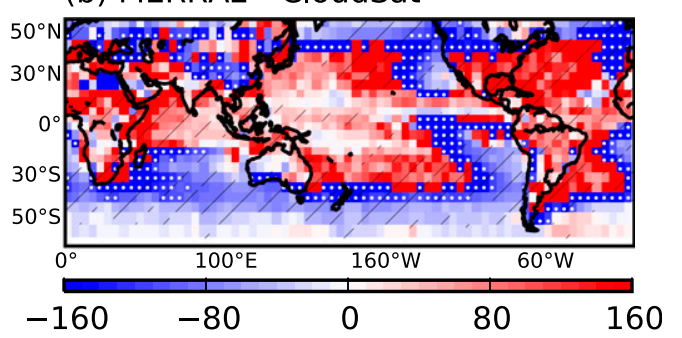

(d) MERRA - CloudSat

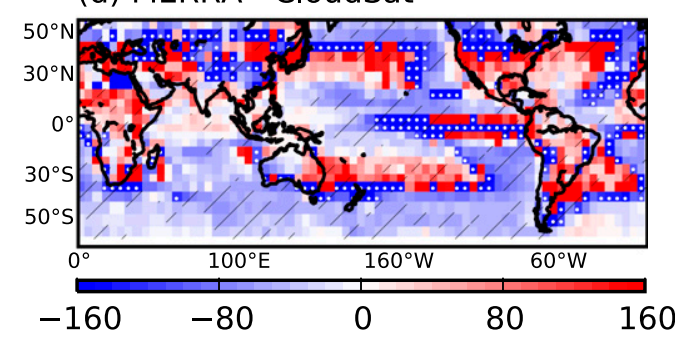

(f) ERAI - CloudSat

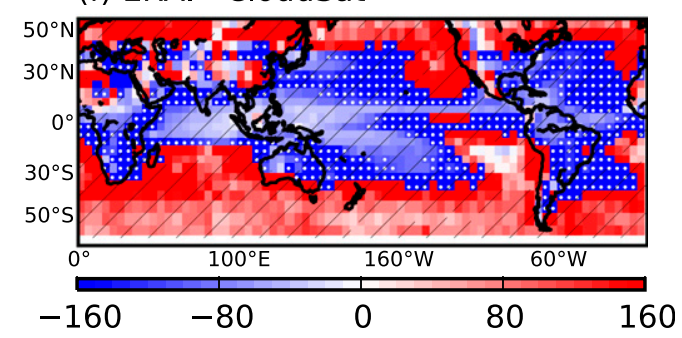

(h) JRA55 - CloudSat

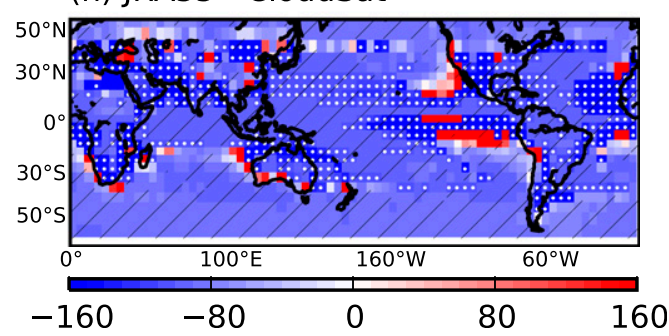

$\begin{array}{lllllll}-1.5 & -1.0 & -0.5 & 0.0 & 0.5 & 1.0 & 1.5\end{array}$

FIG. 7. Mean spatial distribution of $R_{h}$ for the (left) reanalyses for (a) MERRA-2, (c) MERRA, (e) ERAInterim, and (g) JRA-55; and the (right) bias (\%) for (b) MERRA-2 - CloudSat, (d) MERRA - CloudSat, (f) ERA-Interim - CloudSat, and (h) JRA-55 - CloudSat from 2007 to 2010. The white dots indicate where CloudSat and the reanalyses have a different sign. Black hatches indicate where the differences are significant at the $99 \%$ level.

over $20^{\circ} \mathrm{C}$ over a large area $\left(>30 \times 10^{6} \mathrm{~km}^{2}\right)$. This characteristic gave it the name of "heat engine" of the globe; high convective clouds appear in this region and can reach altitudes up to $15 \mathrm{~km}$, generating a lot of latent heat in the process (e.g., De Deckker 2016). This region has generated a lot of interest since a potential increase in SST as a result of anthropogenic activities could trigger a significant decrease in cloud cover. Indeed, Waliser and Graham (1993) and Choi et al. (2017) showed that an increase in SST in the western North
Pacific could cause a decrease in cirrus cloud fraction via an increase in precipitation efficiency. The decrease in cloud fraction could trigger an increase in outgoing LW radiation to a greater degree than SW radiation, creating a potential drop in nocturnal temperature. This could have a huge impact for the populations globally.

Figure 9 shows the seasonal cycles of precipitation, $A_{\text {cld }}, G_{\text {cld }}, N$, and $R_{c}$, respectively, for CloudSat (black line) and reanalyses (colored lines) averaged over the Indo-Pacific warm pool $\left(10^{\circ} \mathrm{S}-10^{\circ} \mathrm{N}, 120^{\circ}-160^{\circ} \mathrm{E}\right)$. The 
(a) RC MERRA2

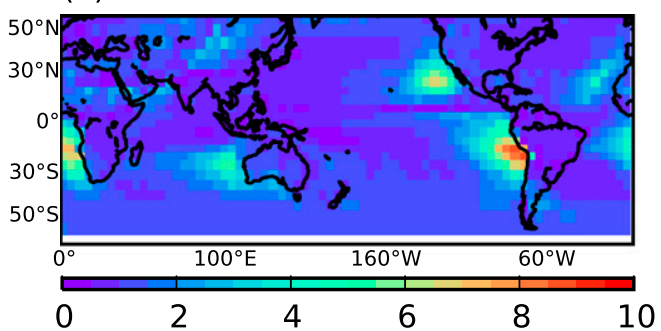

(c) RC MERRA

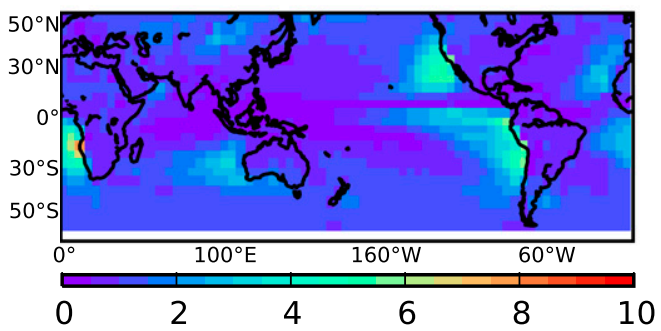

(e) Rc ERAI

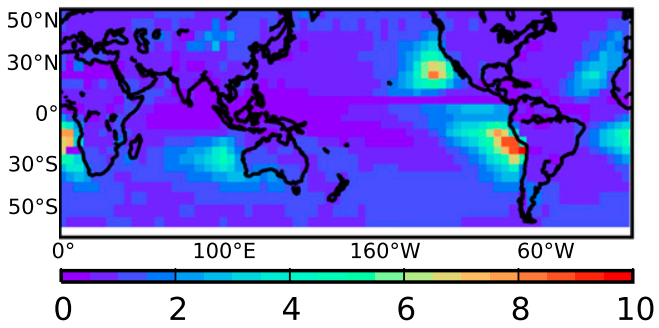

(g) Rc JRA55

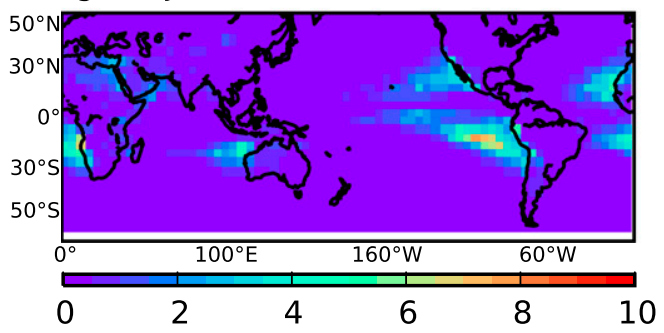

(b) MERRA2 - CloudSat

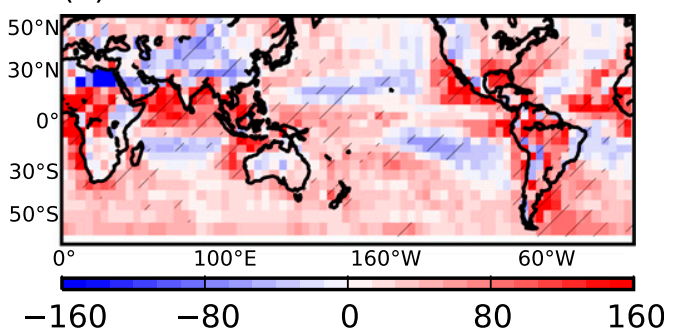

(d) MERRA - CloudSat

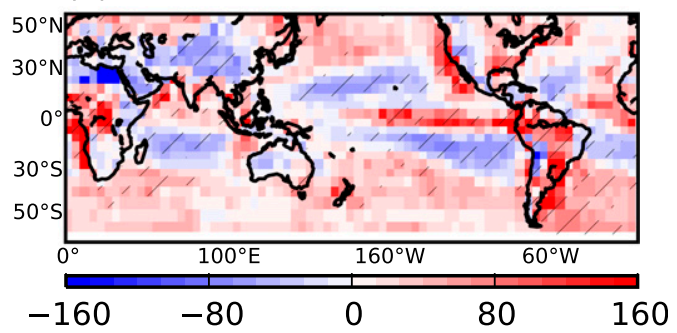

(f) ERAI - CloudSat

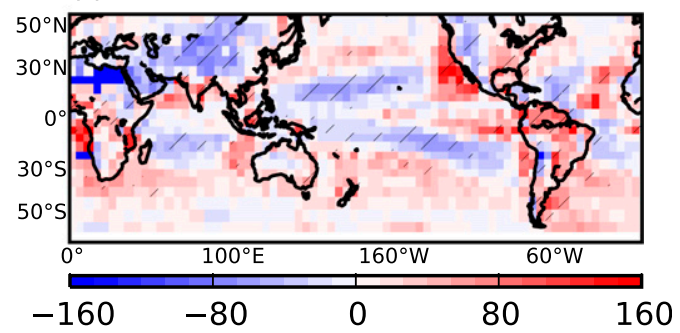

(h) JRA55 - CloudSat

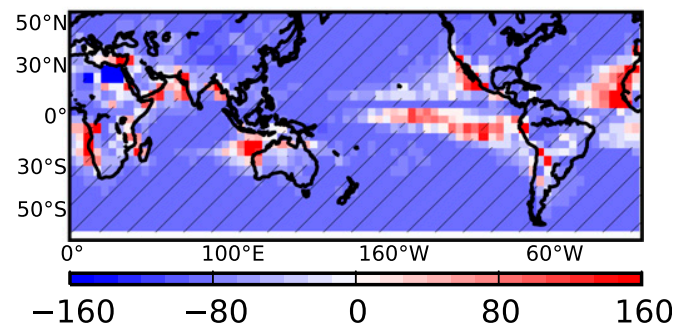

FIG. 8. As in Fig. 4, but for $R_{c}$.

annual variability of the Indo-Pacific warm pool is characterized by a peak in precipitation in April, as shown in Fig. 9a. The peak in precipitation happens simultaneously in the satellite observations and in the reanalyses. Except for JRA-55, reanalyses are able to represent the seasonal cycle of precipitation closely, in terms of both amplitude and pattern. Consistently with the results from the previous sections, the parameters representing the greenhouse (Fig. 9b) and albedo (Fig. 9c) effects of clouds are sensitive to the convective processes of this region. The peaks in precipitation generate a peak in $G_{\text {cld }}$ and $A_{\text {cld }}$ in the satellite observations and most of the reanalyses. Except for JRA-55, which shows no seasonal cycle, the reanalyses capture the peak in cloud greenhouse effect well. JRA-55 also shows a strong bias in amplitude, underestimating $G_{\text {cld }}$ over the region, coherently with Fig. 4. ERA-Interim is closely following CloudSat, while both MERRA datasets overestimate $G_{\text {cld }}$. The peak in albedo $\left(A_{\text {cld }}\right)$ is represented by all the reanalyses, but they all overestimate the amplitude of the effect, coherently with Fig. 5.

Now knowing the biases in SW $\left(A_{\text {cld }}\right)$ and LW $\left(G_{\text {cld }}\right)$ radiation from each reanalysis, it is interesting to look at Fig. 9d, showing the ratio of the SW and LW effects $N$. Understanding where the differences in the amplitude of $N$ stem from is important since they have a large 
a) PREC

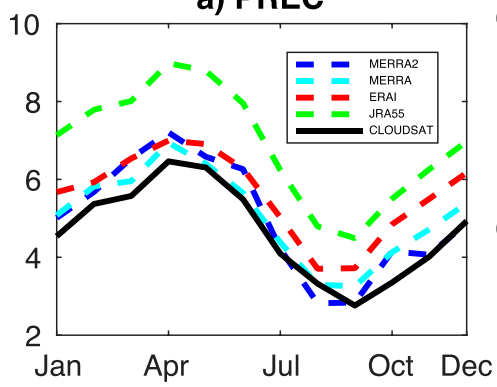

d) $\mathbf{N}$

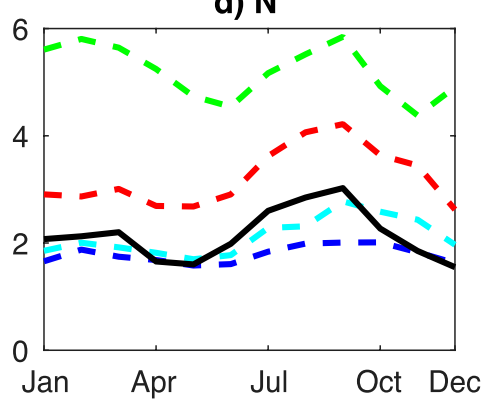

b) Gcld

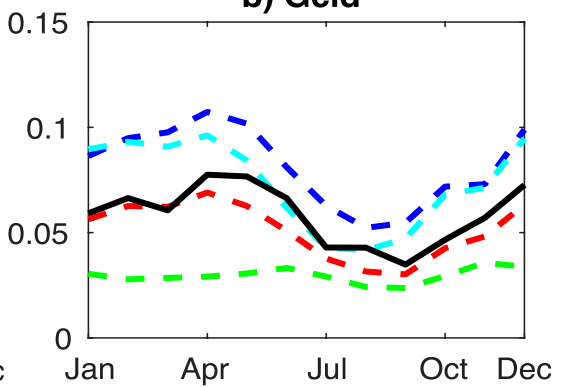

c) Acld

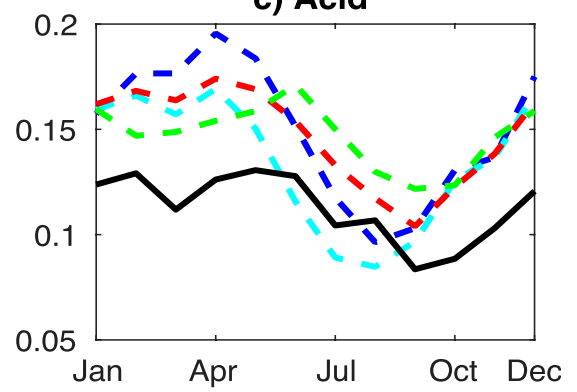

e) Rc

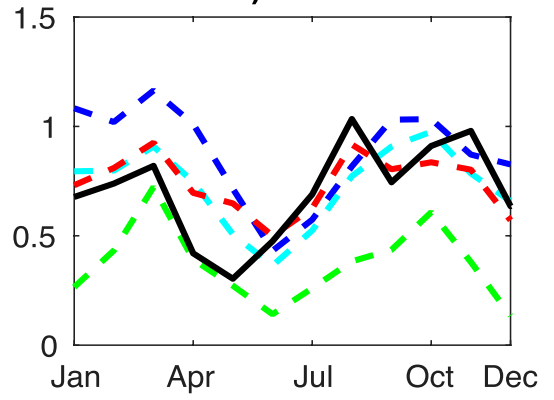

FIG. 9. Seasonal cycle of (a) precipitation $\left(\mathrm{mm} \mathrm{day}^{-1}\right)$, (b) $G_{\text {cld }}$, (c) $A_{\text {cld }}$, (d) $N$, and (e) $R_{c}$ over the warm pool region $\left(10^{\circ} \mathrm{S}-10^{\circ} \mathrm{N}, 120^{\circ}-\right.$ $160^{\circ} \mathrm{E}$ ) for the time period 2007-10 for CloudSat (black line), MERRA-2 (dashed dark blue line), MERRA (dashed light blue line), ERAInterim (dashed red line), and JRA-55 (dashed green line).

impact on the cooling of the atmosphere and therefore the global energy budget. All the reanalyses capture the pattern of the seasonal cycle, showing a peak during the second half of the cycle in September. If only $N$ was examined, both MERRA datasets would have appeared to be the best fit for looking at processes over the Indo-Pacific warm pool, as they very closely follow the observed seasonal cycle of $N$ over the Indo-Pacific warm pool. However, Figs. $9 \mathrm{~b}$ and $9 \mathrm{c}$ show that this result is due to a compensating effect of biases on the greenhouse and albedo effect of clouds, both of which are overestimated in both MERRA datasets. ERAInterim overestimates $N$ and therefore warms the atmosphere too much; this bias comes from its overestimate in $A_{\text {cld }}$ because $G_{\text {cld }}$ is well represented by this dataset. Finally, the strong overestimate in $N$ for JRA-55 comes from an underestimate in $G_{\text {cld }}$ and an overestimate in $A_{\text {cld. }}$.

In addition to the analysis of the radiation-centric parameters, the examination of the energy and water cycle parameter $\left(R_{c}\right)$ provides valuable insights into the coupling of clouds and precipitation in the region. Figure 9e shows that the radiative cooling from precipitating clouds in the Indo-Pacific warm pool is more than offset by latent heating, as $R_{c}$ 's values are under 1 . This is true for all the datasets, except MERRA-2, during the early part of the seasonal cycle. In addition, Fig. 9e shows two peaks in surface radiative cooling for
CloudSat and the reanalyses: one in March and one in September. The first peak must be coming from a peak in cloud albedo preceding the peak in precipitation. Then, $R_{c}$ stays low during summer due to a minimum in cloud cover and finally reaches another peak when precipitation drops off (cf. Fig. 9a). This second peak must be due to a higher amplitude in precipitation, compared to cloud albedo. This difference in timing of clouds versus precipitation is interesting, as well as the ability of the different datasets to capture this pattern, which could be partly the result of the short time period not capturing ENSO variations well. Except JRA-55, all the reanalyses present higher values in $R_{c}$, compared to CloudSat. This point deserves more investigation (to follow), but it already shows that $R_{c}$ is able to provide information on the surface radiative cooling from clouds, the origin of this cooling and the magnitude of compensation by precipitation heating, and the physical processes that lead to these patterns, which makes it very valuable.

\section{b. Seasonal cycle of the stratocumulus clouds in the northeast Pacific Ocean}

As seen in previous sections, the eastern parts of the subtropical oceans typically present an area with persistent stratocumulus clouds (Klein and Hartmann 1993). These clouds are optically thick and are over a dark ocean. They are therefore an important component 
a) Low Clouds

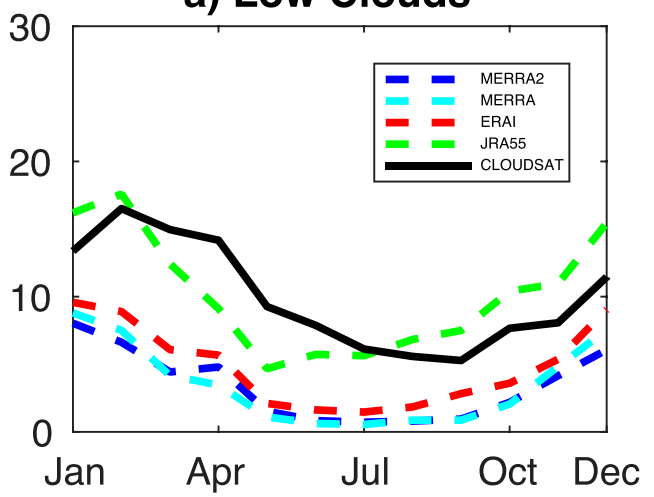

c) PREC

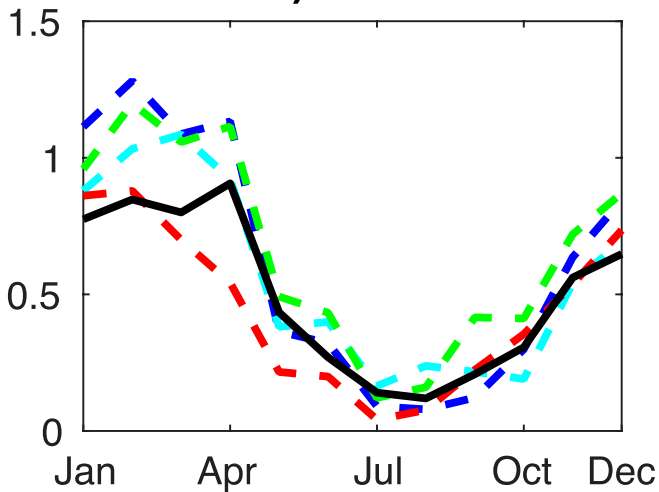

b) Rc

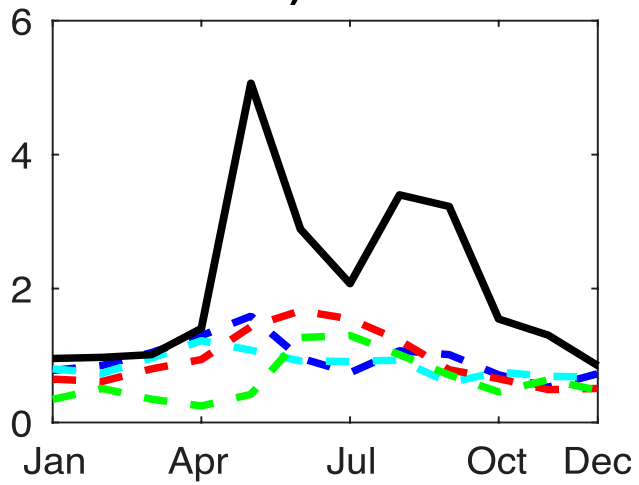

d) Acld

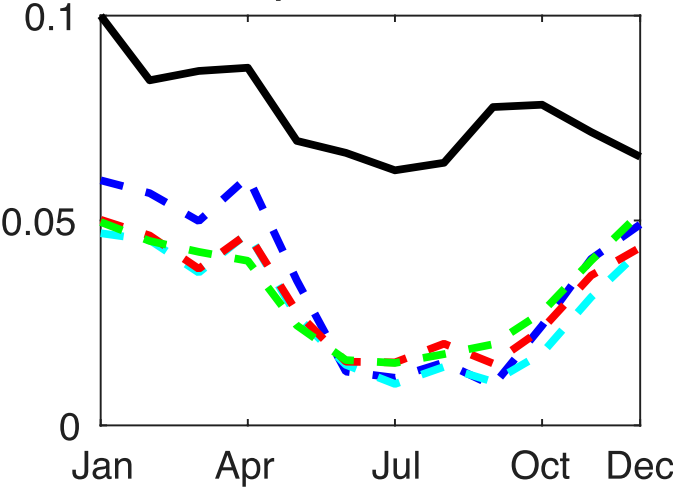

FIG. 10. Seasonal cycle of (a) low cloud fraction (\%), (b) $R_{c}$, (c) precipitation, and (d) $A_{\text {cld }}$ over the northeast Pacific Ocean $\left(20^{\circ}-40^{\circ} \mathrm{N}, 140^{\circ}-120^{\circ} \mathrm{W}\right)$ for the time period $2007-10$ for CloudSat (black line), MERRA-2 (dashed dark blue line), MERRA (dashed light blue line), ERA-Interim (dashed red line), and JRA-55 (dashed green line).

in the amount of solar radiation absorbed by the Earth system. The representation of these clouds is difficult for reanalyses (Duynkerke and Teixeira 2001; Stevens et al. 2007) and represents a key uncertainty for the projections of the temperature response for a doubling of $\mathrm{CO}_{2}$ scenario for climate models (Bony and Dufresne 2005). The marine stratocumulus off the California coast is a classic example of a subtropical region where stratocumulus clouds dominate and will be the focus of this section.

The seasonal cycle of the northeast Pacific subtropical region is presented in Fig. 10 for low cloud fraction, $R_{c}$, precipitation, and $A_{\text {cld }}$, respectively, for CloudSat (black line) and reanalyses (colored dashed lines). In satellite observations and reanalyses, the seasonal cycle of low cloud fraction is characterized by high values during the first half of the cycle when stratocumulus prevail and low values during the second half when the stratocumulus deck transforms into cumulus. In this context, we only look at cloud fraction to get a sense of the climate of the area; it is not employed as a cloud metric for understanding the biases in reanalyses. As mentioned before, $R_{c}$ is a parameter well suited for looking at processes related to stratocumulus clouds. The observed seasonal cycle of the parameter $R_{c}$ (Fig. 10b) is indeed sensitive to the processes in stratocumulus regions and shows a peak in the first (March) and second (August) half of the seasonal cycle, with values up to 5 times higher in March, compared to January or December. However, these peaks are highly underestimated by the reanalyses. Based on the definition of $R_{c}$ [cf. Eq. (4)], this bias can come from a misrepresentation of precipitation via the latent heating (denominator) or radiative cooling (nominator). The next panel shows the seasonal cycle of precipitation (Fig. 10c) in the observations and reanalyses. Reanalyses present a seasonal cycle very similar to the satellite observations, so the bias in $R_{c}$ cannot come from a bias in the representation of the latent heating. Now looking at the radiative cooling through clouds $\left(A_{\text {cld }}\right.$, Fig. 10d), all reanalyses largely underestimate the albedo effect of clouds in this region and similarly underestimate the cooling effect of 
clouds. The bias in $R_{c}$ in all reanalyses is therefore stemming from a bias in the representation of the radiative cooling from clouds and not a bias in the representation of precipitation.

\section{c. Relationship between the CIPs and the large-scale circulation}

A question that now arises is whether the CIPs exhibit any general relationship to the large-scale circulation across the globe. While a comprehensive answer to this question requires analysis that is beyond the scope of this introductory study, Fig. 11 presents a brief summary of the dependence of the five CIPs on $\Omega$ at $500 \mathrm{hPa}$ (omega500) in both the CloudSat observations and the four reanalysis datasets, over the tropics $\left(30^{\circ} \mathrm{N}-30^{\circ} \mathrm{S}\right)$ from 2007 to 2010. Negative values of omega500 are related to regions of large-scale ascent, like the ITCZ, while positive values correspond to subsidence regions, like the marine stratocumulus decks of the east side of the oceans. The spatial resolution of all the datasets has been increased to a $2.5^{\circ} \times 2.5^{\circ}$ grid to more directly connect the CIPs and the local environment. In addition, pixels with very low monthly mean rainfall rates (less than $0.02 \mathrm{~mm} \mathrm{~h}^{-1}$ ) have been screened out from the observational estimates since these are not hydrologically relevant and occur infrequently but disproportionately skew the global statistics.

There is clearly a strong connection between the CIPs and their location within the large-scale meridional overturning Hadley circulation. All the CIPs show qualitatively similar trends between the observations and reanalyses, but the latter exhibit large spreads in amplitude over some parts of the distributions. For the radiation-centric parameters $G_{\text {cld }}$ and $A_{\text {cld }}$, as omega500 increases, these two parameters decrease. These trends appear generally in all of the datasets but with different amplitudes. The spread is particularly large in the regions of large-scale ascent. Based on the results from Fig. 11b, when omega500 is negative (positive), reanalyses exhibit larger (smaller) values in $A_{\text {cld }}$, compared to CloudSat, meaning reanalyses are producing brighter clouds than CloudSat in regions of large-scale ascent and dimmer clouds in subsidence regions. The third radiation-centric parameter $(N$; Fig. 11c) also gives interesting insights on the connection with the largescale circulation. The trend is different from $A_{\text {cld }}$ and $G_{\text {cld }}$, with a simultaneous increase in $N$ and omega500. In all datasets except JRA-55, there is a tendency for $N$ to approach 1 in regions of large-scale ascent, consistent with the results from Kiehl (1994). $N$ tends to increase when moving toward regions of increasing subsidence associated with the shift from high to low clouds then decreases in the most stable environments. The different behavior of JRA-55 in $N$ is not surprising, as it is coherent with the results from section $5 \mathrm{a}$ on the IndoPacific warm pool.

Finally, the energy and water coupling parameters also show interesting features, particularly in subsidence regions. When omega500 is negative, $R_{c}$ and $R_{h}$ remain stable for all the datasets. However, when omega500 is positive, $R_{h}$ decreases while $R_{c}$ increases in reanalyses and satellite observations. Also, this demonstrates how clouds become more effective reflectors as subsidence increases. The spread between the datasets clearly increases in these subsidence regions. It is worth pointing out that $R_{h}$ is surprisingly independent of omega500 over a large part of the distribution for large-scale ascent and descent (cf. Fig. 11d). With CloudSat, for example, $R_{h}$ equals 0.2 for omega500 from -0.05 to $0.02 \mathrm{~Pa} \mathrm{~s}^{-1}$. This suggests that cloud radiative heating contributes about $20 \%$ of the total atmospheric diabatic heating and that on large scales, the cloud greenhouse effect and precipitation intensity scale in the same ratio with largescale vertical motion in the atmosphere. However, in strong subsidence regions (omega500 $>0.02 \mathrm{~Pa} \mathrm{~s}^{-1}$ ), the enhanced longwave emission to the surface from shallow clouds exceeds their greenhouse effects, causing the radiative heating efficiency to change signs. In fact, in this regime, cloud cooling offsets up to $40 \%$ of latent heat released from warm rain production. For $R_{c}$, the distribution is only stable in regions of large-scale ascent. All the datasets show an increase in $R_{c}$ when omega500 is positive, and that is where the spread between the datasets increases. Every reanalysis presents a much higher surface cooling efficiency in the region of subsidence, compared to CloudSat. This means that reanalyses generate much more cooling per unit rainfall in subsidence regions than the satellite observations. This is consistent with the tendency of models to produce brighter stratocumulus and lower rain rates (drizzle instead of rain), compared to observations (Ahlgrimm and Forbes 2014).

\section{Summary and conclusions}

This study presents broad characteristics of five CIPs, parameters that measure the coupled radiative and hydrological influences of precipitating cloud systems, in observation and reanalyses. By explicitly connecting radiative and precipitation fluxes, these parameters more directly connect the processes at the root of cloud feedbacks and climate sensitivity. The parameters measure the cloud greenhouse and albedo effects $\left(G_{\text {cld }}\right.$ and $\left.A_{\text {cld }}\right)$, the ratio of cloud shortwave and longwave forcing $(N)$, and the radiative heating and cooling efficiencies of clouds $\left(R_{h}\right.$ and $\left.R_{c}\right)$. The last two parameters, 
a) Gcld

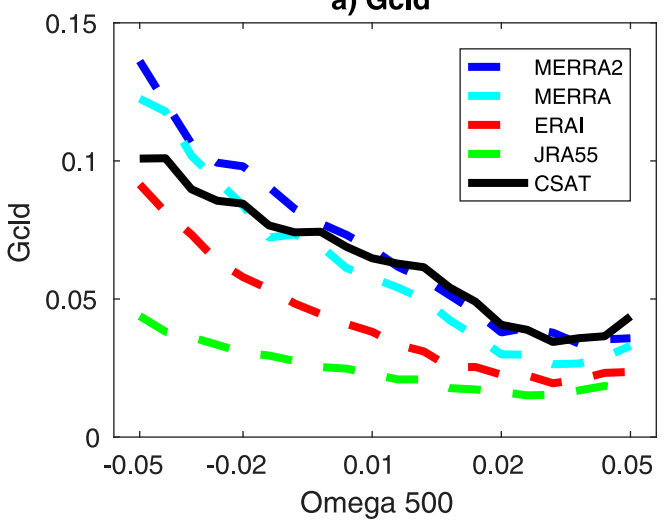

c) $\mathrm{N}$

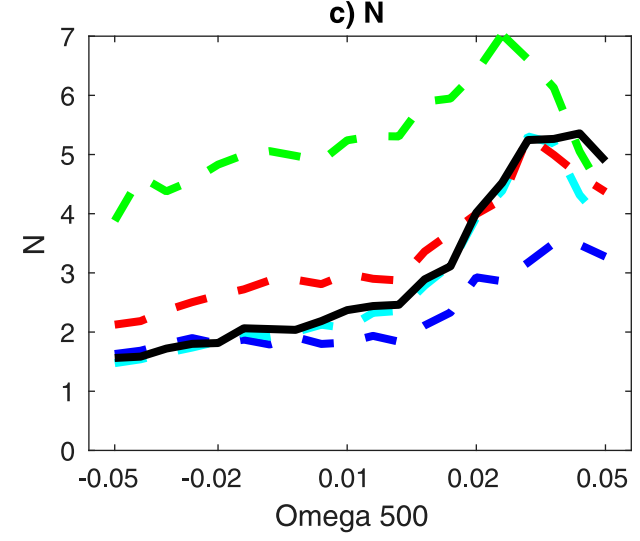

d) $\mathrm{Rh}$

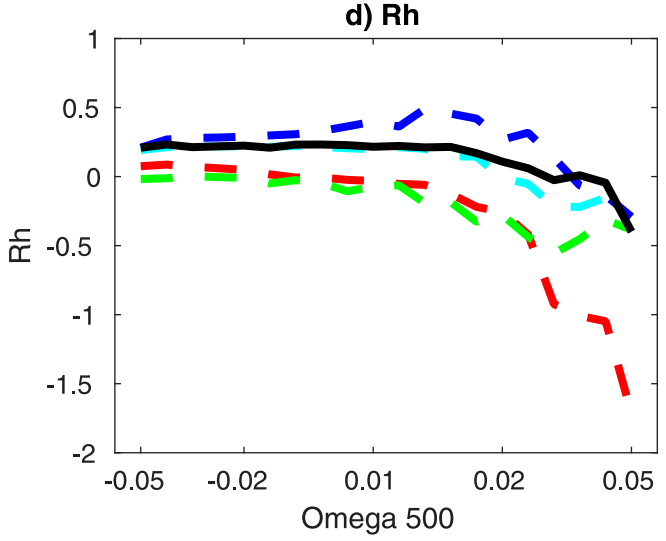

b) Acld

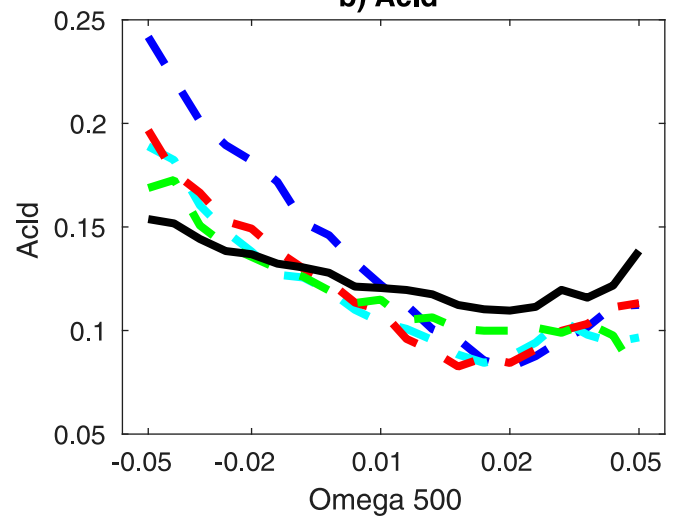

FIG. 11. Distribution of the CIPs as a function of omega at $500 \mathrm{hPa}$ over the tropics $\left(30^{\circ} \mathrm{N}-30^{\circ} \mathrm{S}\right)$ from 2007 to 2010. Omega values are binned into 20 equal percentiles based on the annual mean distribution with bin mean values labeled on the abscissa. Lines show the CloudSat (black), MERRA (dashed light blue), MERRA-2 (dashed dark blue), ERA-Interim (dashed red), and JRA-55 (dashed green) distributions.

in particular, can be connected to complex cloud feedback processes, such as convective aggregation and the impact of shallow low-lying clouds on the surface. To appreciate the information that these parameters can convey, they were first derived from A-Train satellite observations. These observed values were then used to evaluate four modern reanalyses (MERRA, MERRA-2,
ERA-Interim, and JRA-55), identifying some of the strengths and weaknesses of each dataset, as reanalyses can often be used in climate studies or as references for the evaluation of climate models. This study provides only an initial look at composite statistics of these parameters, yet the results already yield insights into model biases. Nevertheless, a deeper dive into regional 
and temporal evolutions is required to fully explain these biases and provide insights for improving models in the future.

In general, the reanalyses provide a more accurate representation of the three radiation-centric parameters $\left(A_{\text {cld }}, G_{\text {cld }}\right.$, and $\left.N\right)$ than the radiative efficiencies $\left(R_{h}\right.$ and $\left.R_{c}\right)$. This is perhaps not surprising, given that many model parameterizations have been tuned to reproduce observed top-of-atmosphere fluxes but generally perform less well at surface fluxes (Soden 2000). The substantial biases in $R_{h}$ and $R_{c}$ and their large variations between reanalyses highlight the challenges of accurately simulating precipitation processes in both stratocumulus and convective cloud regimes. A closer examination of the reanalyses showed that they tend to underestimate the surface cooling $\left(R_{c}\right)$ over the eastern side of tropical oceans and that this bias is due to a misrepresentation of the radiative cooling from clouds. The combination of these biases points to a pathway by which local processes may introduce biases that can have significant implications for global circulations that may ultimately influence cloud feedback and climate sensitivity (e.g., Stevens and Bony 2013; Sherwood et al. 2014; Bony et al. 2015). While the results presented here only document these biases, these results highlight the value of examining radiative efficiencies for better understanding the cause of recurrent deficiencies in the coupled heating and cooling effects of high and low cloud regimes in climate models.

Of the four reanalyses, MERRA and ERA-Interim provide the best overall representations of the different cloud processes represented by the CIPs but can show significant biases in some regions, such as the IndoPacific warm pool. JRA-55 exhibits some clear deficiencies in many parameters. Surprisingly, the new version of MERRA's reanalysis, MERRA-2, introduces biases that were not evident in the previous version of their reanalysis. The parameters related to albedo $\left(A_{\text {cld }}\right.$ or $N$ ) seem to be particularly sensitive to the changes in cloud parameterizations or their coupling to other components of the model implemented in MERRA-2. This may emphasize the influence of the assimilation of aerosols in the newer dataset (Gelaro et al. 2017). The examination of the relationship between the CIPs and the large-scale circulation also emphasizes the importance of working with an ensemble of observational datasets. However, it is interesting to note that over the tropics, MERRA follows closely the distributions of the CIPs from CloudSat, while other reanalyses can show very different behaviors.

The parameters introduced here provide an alternative to more conventional metrics like cloud fraction, cloud radiative effects, and precipitation accumulation that provides deeper insights into the processes driving their occurrence, rather than subjective classifications or measurement of isolated, independent physical quantities. More focused analyses of the northeast Pacific Ocean and the Indo-Pacific warm pool provide examples of how the CIPs can help understand the impact of a bias and where the bias comes from, showing which effect(s) is/are misrepresented. For example, over the northeast Pacific Ocean, the radiative cooling from precipitating clouds $\left(R_{c}\right)$ is not well reproduced by the reanalyses (cf. section 5b). The utility of the CIPs is also demonstrated in the case of comparisons of total cloud cover, where MERRA-2 seemingly performed better than MERRA (not shown) but exhibits strong biases in the representation of the greenhouse effect of clouds over the tropics (cf. section 4a). Furthermore, by explicitly coupling the precipitation and radiative impacts of changing cloud systems, these parameters provide more direct links to cloud feedback processes and climate sensitivity. As a result, they may complement conventional approaches to assessing climate model performance that focus on comparisons against independent parameters in isolation. This study was, however, realized at the monthly time scale and, as such, evaluates the aggregate effects of smaller-scale cloud and precipitation processes within each model or observational grid box. Thus, these broad comparisons cannot provide direct insights into the specific processes that are responsible for the observed biases or a pathway for improving them. There is, however, no practical limitation that precludes applying the same metrics on the shorter time and space scales characteristic of individual cloud systems to examine the complex processes directly. This is the subject of a companion paper by Sun et al. (2018, unpublished manuscript), where the heating and cooling efficiencies $\left(R_{c}\right.$ and $\left.R_{h}\right)$ are estimated from A-Train satellite observations, ERA-Interim, and MERRA-2 reanalyses, and their sensitivities to environmental regime are compared. The dynamic regime appears to act as a switch from weak to strong surface cooling efficiencies and from atmospheric cooling to heating, going from ascent to subsidence regimes. The thermodynamics seems to have the strongest control on the magnitude of the coupling parameters. The magnitude of $R_{c}$ is strongly coupled with the lowertropospheric stability, while $R_{h}$ increases with both increasing sea surface temperature and water vapor. Joint analysis reveals that column water vapor is the primary control on the heating efficiencies. Reanalyses generally capture most of the relationships between the dynamics and the observed cloud impact parameters and between lower-tropospheric stability and surface cooling efficiencies, but fail to capture the strong control by the 
thermodynamic environment of the relationship between atmospheric radiative heating and latent heating from precipitation.

How the cloud radiative forcing will evolve in the future is still unknown, but cloud responses are clearly linked to corresponding changes in precipitation frequency and intensity, since changes in global mean precipitation are constrained by variations in atmospheric radiative cooling (Held and Soden 2006; Stephens and Ellis 2008). In addition, there is evidence that changes in cloud radiative cooling and precipitation are coupled in future climate projections (Pendergrass and Hartmann 2014). The projected increase in global precipitation has long been attributed to the atmospheric energy budget constraint (Mitchell et al. 1987). This implies that the future changes in global mean precipitation are likely to fall within a fairly narrow range. Changes in precipitation frequency and intensity distribution as well as the cloud cover are, however, governed by a complex set of thermodynamic and microphysical processes and much less tightly constrained by global energetics. As a result, changes in the ratio of the cloud radiative impacts to the precipitation yield of these cloud systems, defined here as the radiative efficiencies, govern the strength of cloud feedbacks in the climate system and, therefore, influence climate sensitivity. Thus, further understanding the coupled energetic and hydrologic responses of precipitating cloud regimes to the large-scale circulation is critical for better simulating our climate and therefore improving our confidence in the prediction of regional and global climate change.

Acknowledgments. Work was supported by NASA modeling, analysis, and prediction (MAP) grant, by NASA energy and water cycle study (NEWS) Grant NNX15AD13G, by NASA MAP research Grant NNN12AA01C, and by NASA Headquarters under the NASA Earth and Space Science Fellowship Program Grant NNX14AL35H. CloudSat data were obtained through the CloudSat data processing center (http:// www.cloudsat.cira.colostate.edu/). GPCP data are taken from http://precip.gsfc.nasa.gov. The ERA-Interim data were provided by the European Centre for Medium-Range Weather Forecasts (http://apps.ecmwf.int/datasets/). MERRA data were provided by the Goddard Earth Sciences Data and Information Services Center (https://disc. sci.gsfc.nasa.gov/daac-bin/FTPSubset.pl?LOOKUPID_ List $=$ MAIMCPASM). MERRA-2 data were provided by the Goddard Earth Sciences Data and Information Services Center (https://disc.sci.gsfc.nasa.gov/daac-bin/ FTPSubset2.pl). JRA-55 data were provided by the National Center for Atmospheric Research/University
Corporation for Atmospheric Research (https://rda.ucar. edu/\#!lfd?nb=y\&b=proj\&v=JMA\%20Japanese \%2055year\%20Reanalysis).

\section{REFERENCES}

Adler, R. F., and Coauthors, 2003: The Version-2 Global Precipitation Climatology Project (GPCP) Monthly Precipitation Analysis (1979-present). J. Hydrometeor., 4, 1147-1167, https:// doi.org/10.1175/1525-7541(2003)004<1147:TVGPCP>2.0.CO;2.

—, G. Gu, and G. J. Huffman, 2012: Estimating climatological bias errors for the Global Precipitation Climatology Project (GPCP). J. Appl. Meteor. Climatol., 51, 84-99, https://doi.org/ 10.1175/JAMC-D-11-052.1.

Ahlgrimm, M., and R. Forbes, 2014: Improving the representation of low clouds and drizzle in the ECMWF model based on ARM observations from the Azores. Mon. Wea. Rev., 142, 668-685, https://doi.org/10.1175/MWR-D-13-00153.1.

Bacmeister, J. T., M. J. Suarez, and F. R. Robertson, 2006: Rain reevaporation, boundary layer-convection interactions, and Pacific rainfall patterns in an AGCM. J. Atmos. Sci., 63, 33833403, https://doi.org/10.1175/JAS3791.1.

Bloom, S., L. Takacs, A. da Silva, and D. Ledvina, 1996: Data assimilation using incremental analysis updates. Mon. Wea. Rev., 124, 1256-1271, https://doi.org/10.1175/1520-0493(1996)124<1256: DAUIAU $>2.0 . \mathrm{CO} ; 2$.

Bony, S., and J.-L. Dufresne, 2005: Marine boundary layer clouds at the heart of tropical cloud feedback uncertainties in climate models. Geophys. Res. Lett., 32, L20806, https://doi.org/ 10.1029/2005GL023851.

— sensitivity. Nat. Geosci., 8, 261-268, https://doi.org/10.1038/ ngeo2398.

Bosilovich, M. G., and Coauthors, 2015: MERRA-2: Initial evaluation of the climate. NASA Tech. Rep. NASA/TM2015-104606, 139 pp., https:/gmao.gsfc.nasa.gov/pubs/docs/ Bosilovich803.pdf.

Bretherton, C. S., and A. H. Sobel, 2002: A simple model of a convectively coupled Walker circulation using the weak temperature gradient approximation. J. Climate, 15, 29072920, https://doi.org/10.1175/1520-0442(2002)015<2907: ASMOAC $>2.0 . \mathrm{CO} ; 2$.

- P. N. Blossey, and M. Khairoutdinov, 2005: An energybalance analysis of deep convective self-aggregation above uniform SST. J. Atmos. Sci., 62, 4273-4292, https://doi.org/ 10.1175/JAS3614.1.

Choi, Y.-S., W. Kim, S.-W. Yeh, H. Masunaga, M.-J. Kwon, H.-S. Jo, and L. Huang, 2017: Revisiting the iris effect of tropical cirrus clouds with TRMM and A-Train satellite data. J. Geophys. Res. Atmos., 122, 5917-5931, https://doi.org/10.1002/ 2016JD025827.

Chou, M. D., and M. J. Suarez, 1999: A solar radiation parameterization for atmospheric studies. NASA Tech. Rep. NASA/ TM-1999-104606, 40 pp., https://ntrs.nasa.gov/archive/nasa/ casi.ntrs.nasa.gov/19990060930.pdf.

,-- X. Z. Liang, and M. M. H. Yan, 2001: A thermal infrared radiation parameterization for atmospheric studies. NASA Tech. Rep. NASA/TM-2001-104606, 56 pp., https:// ntrs.nasa.gov/archive/nasa/casi.ntrs.nasa.gov/20010072848.pdf.

Clark, J. V., and J. E. Walsh, 2010: Observed and reanalysis cloud fraction. J. Geophys. Res., 115, D23121, https://doi.org/10.1029/ 2009JD013235. 
Coakley, J. A., R. D. Cess, and F. B. Yurevich, 1983: The effect of tropospheric aerosols on the Earth's radiation budget: A parameterization for climate models. J. Atmos. Sci., 40, 116-138, https://doi.org/10.1175/1520-0469(1983)040<0116: TEOTAO $>2.0 . \mathrm{CO} ; 2$.

Cullather, R. I., S. M. Nowicki, B. Zhao, and M. J. Suarez, 2014: Evaluation of the surface representation of the Greenland Ice Sheet in a general circulation model. J. Climate, 27, 4835-4856, https://doi.org/10.1175/JCLI-D-13-00635.1.

Daloz, A. S., F. Chauvin, K. Walsh, S. Lavender, D. Abbs, and F. Roux, 2012: The ability of general circulation models to simulate tropical cyclones and their precursors over the North Atlantic main development region. Climate Dyn., 39, 15591576, https://doi.org/10.1007/s00382-012-1290-7.

De Deckker, P., 2016: The Indo-Pacific warm pool: Critical to world oceanography and world climate. Geosci. Lett., 3, 20, https://doi.org/10.1186/s40562-016-0054-3.

Dee, D. P., and Coauthors, 2011: The ERA-Interim reanalysis: Configuration and performance of the data assimilation system. Quart. J. Roy. Meteor. Soc., 137, 553-597, https://doi.org/ 10.1002/qj.828.

Del Genio, A. D., Y. Chen, D. Kim, and M. Yao, 2012: The MJO transition from shallow to deep convection in CloudSat/ CALIPSO data and GISS GCM simulations. J. Climate, 25, 3755-3770, https://doi.org/10.1175/JCLI-D-11-00384.1.

Dixon, R. D., A. S. Daloz, D. J. Vimont, and M. Biasutti, 2017: Saharan heat low biases in CMIP5 models. J. Climate, 30, 2867-2884, https://doi.org/10.1175/JCLI-D-16-0134.1.

Dolinar, E. K., X. Dong, and B. Xi, 2016: Evaluation and intercomparison of clouds, precipitation, and radiation budgets in recent reanalyses using satellite-surface observations. Climate Dyn., 46, 2123-2144, https://doi.org/10.1007/s00382-015-2693-z.

Duynkerke, P. G., and J. Teixeira, 2001: Comparison of the ECMWF reanalysis with FIRE I observations: Diurnal variation of marine stratocumulus. J. Climate, 14, 1466-1478, https://doi.org/ 10.1175/1520-0442(2001)014<1466:COTERW>2.0.CO;2.

Gelaro, R., and Coauthors, 2017: The Modern-Era Retrospective Analysis for Research and Applications, version 2 (MERRA-2). J. Climate, 30, 5419-5454, https://doi.org/10.1175/ JCLI-D-16-0758.1.

Gibson, J. K., and Coauthors, 1997: ERA description. ECMWF Re-Analysis Project Report Series, 72 pp.

Hartmann, D. L., H. H. Hendon, and R. A. Houze, 1984: Some implications of the mesoscale circulations in tropical cloud clusters for large-scale dynamics and climate. J. Atmos. Sci., 41, 113-121, https://doi.org/10.1175/1520-0469(1984)041<0113: SIOTMC $>2.0 . \mathrm{CO} ; 2$.

Haynes, J. M., T. S. L'Ecuyer, G. L. Stephens, S. D. Miller, C. Mitrescu, N. B. Wood, and S. Tanelli, 2009: Rainfall retrieval over the ocean with spaceborne W-band radar. J. Geophys. Res., 114, D00A22, https://doi.org/10.1029/2008JD009973.

Held, I. M., and B. J. Soden, 2006: Robust responses of the hydrological cycle to global warming. J. Climate, 19, 5686-5699, https://doi.org/10.1175/JCLI3990.1.

Henderson, D. S., T. L'Ecuyer, G. Stephens, P. Partain, and M. Sekiguchi, 2013: A multisensor perspective on the radiative impacts of clouds and aerosols. J. Appl. Meteor. Climatol., 52, 853-871, https://doi.org/10.1175/JAMC-D-12-025.1.

Heng, Z., Y. Fu, G. Liu, R. Zhou, Y. Wang, R. Yuan, J. Guo, and X. Dong, 2014: A study of the distribution and variability of cloud water using ISCCP, SSM/I cloud product, and reanalysis datasets. J. Climate, 27, 3114-3128, https://doi.org/10.1175/ JCLI-D-13-00031.1.
Holloway, C. E., A. A. Wing, S. Bony, C. Muller, H. Masunaga, T. L'Ecuyer, D. Turner, and P. Zuidema, 2017: Observing convective aggregation. Surv. Geophys., 38, 1199-1236, https:// doi.org/10.1007/s10712-017-9419-1.

Houze, R. A., Jr., 1982: Cloud clusters and large-scale vertical motions in the tropics. J. Meteor. Soc. Japan, 60, 396-410, https://doi.org/10.2151/jmsj1965.60.1_396.

_ 1989 : Observed structure of mesoscale convective systems and implications for large-scale heating. Quart. J. Roy. Meteor. Soc., 115, 425-461, https://doi.org/10.1002/qj.49711548702.

Hsu, P., and T. Li, 2012: Role of the boundary layer moisture asymmetry in causing the eastward propagation of the Madden-Julian oscillation. J. Climate, 25, 4914-4931, https:// doi.org/10.1175/JCLI-D-11-00310.1.

Huffman, G. J., R. F. Adler, D. T. Bolvin, and G. Gu, 2009: Improving the global precipitation record: GPCP Version 2.1. Geophys. Res. Lett., 36, L17808, https://doi.org/10.1029/ 2009GL040000.

Jakob, C., 1999: Cloud cover in ECMWF reanalysis. J. Climate, 12, 947-959, https://doi.org/10.1175/1520-0442(1999)012<0947: CCITER $>2.0 . \mathrm{CO} ; 2$.

- and S. A. Klein, 1999: The role of vertically varying cloud fraction in the parametrization of microphysical processes in the ECMWF model. Quart. J. Roy. Meteor. Soc., 125, 941-965, https://doi.org/10.1002/qj.49712555510.

_ - and — 2000: A parametrization of the effects of cloud and precipitation overlap for use in general-circulation models. Quart. J. Roy. Meteor. Soc., 126, 2525-2544, https://doi.org/ 10.1002/qj.49712656809.

Joseph, J. H., W. J. Wiscombe, and J. A. Weinman, 1976: The delta-Eddington approximation for radiative flux transfer. J. Atmos. Sci., 33, 2452-2459, https://doi.org/10.1175/ 1520-0469(1976)033<2452:TDEAFR >2.0.CO;2.

Kay, J. E., and Coauthors, 2012: Exposing global cloud biases in the Community Atmosphere Model (CAM) using satellite observations and their corresponding instrument simulators. J. Climate, 25, 5190-5207, https://doi.org/10.1175/ JCLI-D-11-00469.1.

Khairoutdinov, M. F., and K. A. Emanuel, 2013: Rotating radiative-convective equilibrium simulated by a cloudresolving model. J. Adv. Model. Earth Syst., 5, 816-825, https://doi.org/10.1002/2013MS000253.

Kiehl, J. T., 1994: On the observed near cancellation between longwave and shortwave cloud forcing in tropical regions. J. Climate, 7, 559-565, https://doi.org/10.1175/1520-0442(1994)007<0559: OTONCB $>2.0 . \mathrm{CO} ; 2$.

Kim, J., and M. J. Alexander, 2013: Tropical precipitation variability and convectively coupled equatorial waves on submonthly time scales in reanalyses and TRMM. J. Climate, 26, 3013-3030, https://doi.org/10.1175/JCLI-D-12-00353.1.

Klein, S. A., and D. L. Hartmann, 1993: The seasonal cycle of low stratiform clouds. J. Climate, 6, 1587-1606, https://doi.org/ 10.1175/1520-0442(1993)006<1587:TSCOLS $>2.0$. CO;2.

Kobayashi, C., H. Endo, T. Ota, S. Kobayashi, H. Onoda, Y. Harada, K. Onogi, and H. Kamahori, 2014: Preliminary results of the JRA-55C, an atmospheric reanalysis assimilating conventional observations only. SOLA, 10, 78-82, https:// doi.org/10.2151/sola.2014-016.

Kobayashi, S., and Coauthors, 2015: The JRA-55 reanalysis: General specifications and basic characteristics. J. Meteor Soc. Japan, 93, 5-48, https://doi.org/10.2151/jmsj.2015-001.

Köhler, M., M. Ahlgrimm, and A. C. M. Beljaars, 2011: Unified treatment of dry convective and stratocumulus-topped 
boundary layers in the ECMWF model. Quart. J. Roy. Meteor. Soc., 137, 43-57, https://doi.org/10.1002/qj.713.

Kummerow, C. D., S. Ringerud, J. Crook, D. Randel, and W. Berg, 2011: An observationally generated a priori database for microwave rainfall retrievals. J. Atmos. Oceanic Technol., 28, 113-130, https://doi.org/10.1175/2010JTECHA1468.1.

Lau, K., and L. Peng, 1987: Origin of low-frequency (intraseasonal) oscillations in the tropical atmosphere. Part I: Basic theory. J. Atmos. Sci., 44, 950-972, https://doi.org/10.1175/ 1520-0469(1987)044<0950:OOLFOI >2.0.CO;2.

L'Ecuyer, T. S., and J. H. Jiang, 2010: Touring the atmosphere aboard the A-Train. Phys. Today, 63, 36-41, https://doi.org/ 10.1063/1.3463626.

- H. Masunaga, and C. Kummerow, 2006: Variability in the characteristics of precipitation systems in the tropical Pacific. Part II: Implications for atmospheric heating. J. Climate, 19, 1388-1406, https://doi.org/10.1175/JCLI3698.1.

- N. B. Wood, T. Haladay, G. L. Stephens, and P. W. Stackhouse Jr., 2008: Impact of clouds on atmospheric heating based on the R04 CloudSat fluxes and heating rates data set. J. Geophys. Res., 113, D00A15, https://doi.org/10.1029/ 2008JD009951.

Lee, M.-I., I.-S. Kang, J.-K. Kim, and B. E. Mapes, 2001: Influence of cloud-radiation interaction on simulating tropical intraseasonal oscillation with an atmospheric general circulation model. J. Geophys. Res., 106, 14219-14233, https://doi.org/ 10.1029/2001JD900143.

Lenaerts, J. T. M., K. Van Tricht, S. Lhermitte, and T. S. L'Ecuyer, 2017: Polar clouds and radiation in satellite observations, reanalyses, and climate models. Geophys. Res. Lett., 44, 33553364, https://doi.org/10.1002/2016GL072242.

Li, J., W. C. Wang, X. Dong, and J. Mao, 2017: Cloud-radiationprecipitation associations over the Asian monsoon region: An observational analysis. Climate Dyn., 49, 3237-3255, https:// doi.org/10.1007/s00382-016-3509-5.

Liu, Y., and J. R. Key, 2016: Assessment of Arctic cloud cover anomalies in atmospheric reanalysis products using satellite data. J. Climate, 29, 6065-6083, https://doi.org/10.1175/ JCLI-D-15-0861.1.

Lock, A. P., A. R. Brown, M. R. Bush, G. M. Martin, and R. N. B. Smith, 2000: A new boundary layer mixing scheme. Part I: Scheme description and single-column model tests. Mon. Wea. Rev., 128, 3187-3199, https://doi.org/10.1175/1520-0493(2000)128<3187: ANBLMS $>2.0 . \mathrm{CO} ; 2$.

Louis, J., M. Tiedtke, and J. Geleyn, 1982: A short history of the PBL parameterization at ECMWF. Proc. ECMWF Workshop on Planetary Boundary Layer Parameterization, Reading, United Kingdom, ECMWF, 59-80, https://www.ecmwf.int/en/ elibrary/10845-short-history-pbl-parameterization-ecmwf.

Mapes, B. E., and R. A. Houze Jr., 1995: Diabatic divergence profiles in western Pacific mesoscale convective systems. J. Atmos. Sci., 52, 1807-1828, https://doi.org/10.1175/ 1520-0469(1995)052<1807:DDPIWP>2.0.CO;2.

Matus, A. V., and T. S. L'Ecuyer, 2017: The role of cloud phase in Earth's radiation budget. J. Geophys. Res. Atmos., 122, 25592578, https://doi.org/10.1002/2016JD025951.

Mitchell, J. F., C. A. Wilson, and W. M. Cunnington, 1987: On $\mathrm{Co}_{2}$ climate sensitivity and model dependence of results. Quart. J. Roy. Meteor. Soc., 113, 293-322, https://doi.org/10.1256/ smsqj. 47516.

Mlawer, E. J., S. J. Taubman, P. D. Brown, M. J. Iacono, and S. A. Clough, 1997: Radiative transfer for inhomogeneous atmospheres: RRTM, a validated correlated-k model for the longwave. J. Geophys. Res., 102, 16 663-16 682, https://doi.org/ 10.1029/97JD00237.

Molod, A., L. Takacs, M. Suarez, and J. Bacmeister, 2015: Development of the GEOS-5 atmospheric general circulation model: Evolution from MERRA to MERRA2. Geosci. Model Dev., 8, 1339-1356, https://doi.org/10.5194/gmd-8-1339-2015.

Moorthi, S., and M. J. Suarez, 1992: Relaxed Arakawa-Schubert. A parameterization of moist convection for general circulation models. Mon. Wea. Rev., 120, 978-1002, https://doi.org/ 10.1175/1520-0493(1992)120<0978:RASAPO > 2.0.CO;2.

Nam, C., and J. Quaas, 2012: Evaluation of clouds and precipitation in the ECHAM5 general circulation model using CALIPSO and CloudSat satellite data. J. Climate, 25, 4975-4992, https:// doi.org/10.1175/JCLI-D-11-00347.1.

Nelson, E. L., and T. S. L'Ecuyer, 2018: Global character of latent heat release in oceanic warm rain systems. J. Geophys. Res. Atmos., 123, 4797-4817, https://doi.org/10.1002/2017JD027844. , S. M. Saleeby, W. Berg, S. R. Herbener, and S. C. van den Heever, 2016: Toward an algorithm for estimating latent heat release in warm rain systems. J. Atmos. Oceanic Technol., 33, 1309-1329, https://doi.org/10.1175/JTECH-D-15-0205.1.

Nesbitt, S. W., and E. J. Zipser, 2003: The diurnal cycle of rainfall and convective intensity according to three years of TRMM measurements. J. Climate, 16, 1456-1475, https://doi.org/ 10.1175/1520-0442-16.10.1456.

Nolan, D. S., Y. Moon, and D. P. Stern, 2007: Tropical cyclone intensification from asymmetric convection: Energetics and efficiency. J. Atmos. Sci., 64, 3377-3405, https://doi.org/10.1175/ JAS3988.1.

Pendergrass, A. G., and D. L. Hartmann, 2014: The atmospheric energy constraint on global-mean precipitation change. J. Climate, 27, 757-768, https://doi.org/10.1175/JCLI-D-13-00163.1.

Pincus, R., C. P. Batstone, R. J. P. Hofmann, K. E. Taylor, and P. J. Glecker, 2008: Evaluating the present-day simulation of clouds, precipitation, and radiation in climate models. J. Geophys. Res., 113, D14209, https://doi.org/10.1029/ 2007JD009334.

Räisänen, P., 1998: Effective longwave cloud fraction and maximum-random overlap of clouds: A problem and a solution. Mon. Wea. Rev., 126, 3336-3340, https://doi.org/10.1175/ 1520-0493(1998)126<3336:ELCFAM>2.0.CO;2.

Reichler, T., and J. Kim, 2008: Uncertainties in the climate mean state of global observations, reanalyses, and the GFDL climate model. J. Geophys. Res., 113, D05106, https://doi.org/ 10.1029/2007JD009278.

Rienecker, M. M., and Coauthors, 2011: MERRA: NASA's Modern-Era Retrospective Analysis for Research and Applications. J. Climate, 24, 3624-3648, https://doi.org/10.1175/ JCLI-D-11-00015.1.

Schumacher, C., R. A. Houze Jr., and I. Kraucunas, 2004: The tropical dynamical response to latent heating estimates derived from the TRMM precipitation radar. J. Atmos. Sci., 61, 1341-1358, https://doi.org/10.1175/1520-0469(2004)061<1341: TTDRTL $>2.0 . \mathrm{CO} ; 2$

Sherwood, S. C., S. Bony, and J.-L. Dufresne, 2014: Spread in model climate sensitivity traced to atmospheric convective mixing. Nature, 505, 37-42, https://doi.org/10.1038/nature12829.

Slingo, A., and J. M. Slingo, 1988: The response of a general circulation model to cloud longwave radiative forcing. I: Introduction and initial experiments. Quart. J. Roy. Meteor. Soc., 114, 1027-1062, https://doi.org/10.1002/qj.49711448209.

, and _ 1991: Response of the National Center for Atmospheric Research community climate model to improvements 
in the representation of clouds. J. Geophys. Res., 96, 1534115 357, https://doi.org/10.1029/91JD00930.

Sobel, A. H., and C. S. Bretherton, 2000: Modeling tropical precipitation in a single column. J. Climate, 13, 4378-4392, https:// doi.org/10.1175/1520-0442(2000)013<4378:MTPIAS>2.0.CO;2.

— , and H. Gildor, 2003: A simple time-dependent model of SST hot spots. J. Climate, 16, 3978-3992, https://doi.org/10.1175/ 1520-0442(2003)016<3978:ASTMOS>2.0.CO;2.

Soden, B. J., 2000: The sensitivity of the tropical hydrologic cycle to ENSO. J. Climate, 13, 538-549, https://doi.org/10.1175/ 1520-0442(2000)013<0538:TSOTTH >2.0.CO;2.

— , and I. M. Held, 2006: An assessment of climate feedbacks in coupled ocean-atmosphere models. J. Climate, 19, 3354-3360, https://doi.org/10.1175/JCLI3799.1.

Stein, T. H., C. E. Holloway, I. Tobin, and S. Bony, 2017: Observed relationships between cloud vertical structure and convective aggregation over tropical ocean. J. Climate, 30, 2187-2207, https://doi.org/10.1175/JCLI-D-16-0125.1.

Stephens, G. L., 2005: Cloud feedbacks in the climate system: A critical review. J. Climate, 18, 237-273, https://doi.org/10.1175/ JCLI-3243.1.

_, and T. J. Greenwald, 1991: The Earth's radiation budget and its relation to atmospheric hydrology: 2. Observations of cloud effects. J. Geophys. Res., 96, 15 325-15340, https://doi.org/ 10.1029/91JD00972.

—, and T. D. Ellis, 2008: Controls of global-mean precipitation increases in global warming GCM experiments. J. Climate, 21, 6141-6155, https://doi.org/10.1175/2008JCLI2144.1.

— , and Coauthors, 2008: CloudSat mission: Performance and early science after the first year of operation. J. Geophys. Res., 113, D00A18, https://doi.org/10.1029/2008JD009982.

, D. Winker, J. Pelon, C. Trepte, D. Vane, C. Yuhas, T. L'Ecuyer, and M. Lebsock, 2017: CloudSat and CALIPSO within the A-Train: Ten years of actively observing the Earth system. Bull. Amer. Meteor. Soc., 99, 569-581, https://doi.org/ 10.1175/BAMS-D-16-0324.1.

Stevens, B., and S. Bony, 2013: What are climate models missing? Science, 340, 1053-1054, https://doi.org/10.1126/science.1237554.
— A. Beljaars, S. Bordoni, C. Holloway, M. Köhler, S. Krueger, V. Savic-Jovcic, and Y. Y. Zhang, 2007: On the structure of the lower troposphere in the summertime stratocumulus regime of the northeast Pacific. Mon. Wea. Rev., 135, 985-1005, https://doi.org/10.1175/MWR3427.1.

Tanelli, S., S. L. Durden, E. Im, K. S. Pak, D. G. Reinke, P. Partain, J. M. Haynes, and R. T. Marchand, 2008: CloudSat's Cloud Profiling Radar after two years in orbit: Performance, calibration, and processing. IEEE Trans. Geosci. Remote Sens., 46, 3560-3573, https://doi.org/10.1109/TGRS.2008.2002030.

Teixeira, J., and Coauthors, 2011: Tropical and subtropical cloud transitions in weather and climate prediction models: The GCSS/WGNE Pacific Cross-Section Intercomparison (GPCI). J. Climate, 24, 5223-5256, https://doi.org/10.1175/ 2011JCLI3672.1.

Tobin, I., S. Bony, and R. Roca, 2012: Observational evidence for relationships between the degree of aggregation of deep convection, water vapor, surface fluxes, and radiation. J. Climate, 25, 6885-6904, https://doi.org/10.1175/JCLI-D-11-00258.1.

Uppala, S. M., and Coauthors, 2005: The ERA-40 re-analysis. Quart. J. Roy. Meteor. Soc., 131, 2961-3012, https://doi.org/ 10.1256/qj.04.176.

Waliser, D. E., and N. E. Graham, 1993: Convective cloud systems and warm-pool sea surface temperatures: Coupled interactions and self-regulation. J. Geophys. Res., 98, 1288112 893, https://doi.org/10.1029/93JD00872.

Walsh, J. E., W. L. Chapman, and D. H. Portis, 2009: Arctic cloud fraction and radiative fluxes in atmospheric reanalyses. J. Climate, 22, 2316-2334, https://doi.org/10.1175/2008JCLI2213.1.

Wang, M., and Coauthors, 2012: Constraining cloud lifetime effects of aerosols using A-Train satellite observations. Geophys. Res. Lett., 39, L15709, https://doi.org/10.1029/2012GL052204.

Weaver, A. J., 1999: Extratropical subduction and decadal modulation of El Niño. Geophys. Res. Lett., 26, 743-746, https://doi.org/ 10.1029/1999GL900102.

Xie, S., and M. Zhang, 2000: Impact of the convection triggering function on single-column model simulations. J. Geophys. Res., 105, 14 983-14 996, https://doi.org/10.1029/2000JD900170. 